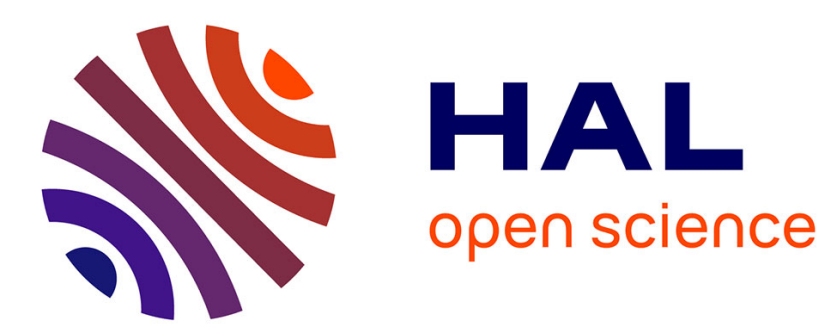

\title{
Convective-Reactive Transport of Dissolved CO2 in Fractured-Geological Formations
}

Paiman Shafabakhsh, Behzad Ataie-Ashtiani, Craig T Simmons, Anis Younes, Marwan Fahs

\section{- To cite this version:}

Paiman Shafabakhsh, Behzad Ataie-Ashtiani, Craig T Simmons, Anis Younes, Marwan Fahs. Convective-Reactive Transport of Dissolved CO2 in Fractured-Geological Formations. International Journal of Greenhouse Gas Control, 2021, 10.1016/j.ijggc.2021.103365 hal-03432672

\section{HAL Id: hal-03432672 \\ https://hal.science/hal-03432672}

Submitted on 17 Nov 2021

HAL is a multi-disciplinary open access archive for the deposit and dissemination of scientific research documents, whether they are published or not. The documents may come from teaching and research institutions in France or abroad, or from public or private research centers.
L'archive ouverte pluridisciplinaire HAL, est destinée au dépôt et à la diffusion de documents scientifiques de niveau recherche, publiés ou non, émanant des établissements d'enseignement et de recherche français ou étrangers, des laboratoires publics ou privés. 


\section{Convective-Reactive Transport of Dissolved $\mathrm{CO}_{2}$ in Fractured- Geological Formations}

Paiman Shafabakhsh ${ }^{1}$, Behzad Ataie-Ashtiani ${ }^{1,2}$, Craig T. Simmons ${ }^{2}$, Anis Younes ${ }^{3}$, Marwan Fahs $^{3, *}$

1 Department of Civil Engineering, Sharif University of Technology, PO Box 11155-9313, Tehran, Iran

2 National Centre for Groundwater Research \& Training, College of Science \& Engineering,

Flinders University, GPO Box 2100, Adelaide, South Australia 5001, Australia

3 Université de Strasbourg, CNRS, ENGEES, LHYGES UMR 7517, F-67000 Strasbourg, France

* Corresponding author: Marwan Fahs (fahs@ unistra.fr)

Submitted to: International Journal of Greenhouse Gas Control

Keywords: $\mathrm{CO}_{2}$ geological sequestration; Carbonate-fractured formations; Geochemical reactions; Density-driven convection; Outcrop analysis 


\begin{abstract}
:
Carbon dioxide $\left(\mathrm{CO}_{2}\right)$ storage in geologic formations is an attractive means of reducing greenhouse gas emissions. The main processes controlling the migration of $\mathrm{CO}_{2}$ in geological formations are related to convective mixing and geochemical reactions. The effects of heterogeneity on these coupled processes have been widely discussed in the literature. Recently, special attention has been devoted to fractured geological formations that can be found in several storage reservoirs. However, existing studies on the effect of fractures on the fate of $\mathrm{CO}_{2}$ neglect the key processes of geochemical reactions. This work aims at addressing this gap. Based on numerical simulations of a hypothetical reservoir, we explore the effect of fracture properties and topology on the domain's storage capacity at different rates of $\mathrm{CO}_{2}$ mineral dissolution. It is found that, the fractures not only can help the mixing convection and reaction process in the domain but also may play a restrictive role in entering dissolved $\mathrm{CO}_{2}$ and hinder the plume fingers from growing. The hypothetical case is relevant in providing preliminary understanding but can show varying degrees of geological realism. For more representative geology, we investigate the migration-dissolution of buoyant $\mathrm{CO}_{2}$ on a large-scale outcrop of a volcanic basalt rock formation. The results show that neglecting thin fractures can significantly affect the predicted amount of trapped $\mathrm{CO}_{2}$. The storage capacity is more sensitive to heterogeneity at low dissolution rates. The findings are useful for the management of $\mathrm{CO}_{2}$ sequestration in fractured domains.
\end{abstract}




\section{Introduction}

Energy transition, sustainable development, and climate change are currently the main significant challenges facing humanity. Since the mid-20th century, due to anthropogenic greenhouse gas emissions and activities, global warming has been raised, and the increase in global temperature is estimated at $0.2^{\circ} \mathrm{C}$ above pre-industrial levels (Masson-Delmotte et al., 2018). This caused various observed changes in the climate system, such as the melting of the ice caps, sea-level rise, intensified heatwaves, and longer drought periods in most semiarid regions (NASA, 2018). The Intergovernmental Panel on Climate Change (IPCC) predicts a temperature rise of 1 to $6^{\circ} \mathrm{C}$ by the end of the century, and the impact of climate change on humanity varies with the ability of social systems to adapt or mitigate changes (Masson-Delmotte et al., 2018).

It is assessed that the major reason for the increase in the global temperature of the Earth's surface is the multiple anthropogenic sources that cause the accumulation of greenhouse gas in the atmosphere (Rose et al., 2017). Carbon dioxide $\left(\mathrm{CO}_{2}\right)$ is the primary greenhouse gas; therefore, considerable mitigation of $\mathrm{CO}_{2}$ emissions is the most effective way to reduce global warming (NASA, 2018). This calls for new sources of low-carbon energy. But in a transition period, there is a need for efficient techniques to reduce $\mathrm{CO}_{2}$ emission to the atmosphere. Among several available techniques, the storage of $\mathrm{CO}_{2}$ in geological formations is one of the leading technological ways to dramatically reduce anthropogenic emissions of greenhouse gas (Bachu et al., 2007; Gough, 2016; Michael et al., 2010; Orr, 2009). Injecting $\mathrm{CO}_{2}$ into oil- and brine-bearing reservoirs is a technology to store captured anthropogenic $\mathrm{CO}_{2}$ beneath the Earth's surface. The sequestration of $\mathrm{CO}_{2}$ process for mitigating greenhouse gas involves the capture and transportation of $\mathrm{CO}_{2}$ from anthropogenic sources and then injecting of supercritical $\mathrm{CO}_{2}$ into underground geologic formations (Boot-Handford et al., 2014). The Paris Agreement on climate change estimated 
that this technique would have a pivotal role in reducing greenhouse gas emissions (Rogelj et al., 2016).

$\mathrm{CO}_{2}$ geological sequestration is a complex technology that involves a consecutive series of capture, transport, and sequestration/trapping processes. It requires knowledge and skills from geology, fluid mechanics, chemistry, geochemistry, hydrogeology, and environmental science. Current research questions in $\mathrm{CO}_{2}$ geological sequestration focus on the improvement of the injection techniques (Hoteit et al., 2019; Sigfusson et al., 2015), ensuring safe and successful implementation (Romasheva and Ilinova, 2019; Singh and Islam, 2018; Soltanian et al., 2019), enhancement of reservoirs capacity (Kim et al., 2017; Raziperchikola et al., 2013), and assessment and prediction of the geological and environmental impacts (Chen et al., 2018). A key point in addressing these research questions relies on a good understanding of the fate of $\mathrm{CO}_{2}$ in geological formations. The most important processes controlling the injected $\mathrm{CO}_{2}$ are density-driven convection (DDC) and precipitation/dissolution (Kim et al., 2019; Mojtaba et al., 2014). In fact, after injecting supercritical $\mathrm{CO}_{2}$ into a reservoir, because of the buoyancy effects (density and viscosity of $\mathrm{CO}_{2}$ are $70 \%$ and $10 \%$ those of water), $\mathrm{CO}_{2}$ migrates upward to spread over the caprock at the reservoir top surface, and then, it dissolves into the ambient native groundwater (Kim et al., 2019; Mojtaba et al., 2014). This forms the carbonic acid that has a higher density than water. Mixing processes between carbonic acid and lower groundwater take place by molecular diffusion. The density difference between carbonic acid and water induces gravitational instability. Thus, unstable DDC processes occur, and the fingering phenomenon appears. Fingering processes cause an enhancement of the mixing between carbonic acid and water. In the under-layers, the acidified water, in the long term, initiates mineral precipitation/dissolution reactions with the ambient geological formations (Soltanian et al., 2019). 
The processes of DDC dissolution and mineral precipitation are fully coupled. Interactions between these processes during $\mathrm{CO}_{2}$ sequestration have been the subject of several theoretical, numerical, and experimental studies. A widely discussed issue is the $\mathrm{CO}_{2}$ dissolution in resident brine (i.e., solubility trapping) during sequestration in saline aquifers (Emami-Meybodi et al., 2015; Jafari Raad et al., 2019; Mojtaba et al., 2014; Tang et al., 2019). A comprehensive review of modeling and experimental works related to convective dissolution of $\mathrm{CO}_{2}$ in saline aquifers is presented in (Emami-Meybodi et al., 2015). In the underground geologic formations, the dissolution of $\mathrm{CO}_{2}$ in water increases acidity. Thus, under low-pH conditions, several primary minerals of the host rocks dissolve into the formation water. This increases the concentration in cations such as $\mathrm{Ca}^{2+}, \mathrm{Mg}^{2+}$ and $\mathrm{Fe}^{2+}$. $\mathrm{By}$ reactions with the existing cations carbonic, acid can form carbonate minerals such as $\mathrm{CaCO}_{3}$, $\mathrm{MgCO}_{3}$, and $\mathrm{FeCO}_{3}$. This phenomenon is called mineral trapping (Zhang et al., 2011; Soltanian et al., 2019). The reaction rates of the geochemical reactions depend on several in situ conditions such as pressure and temperature (Bachu et al., 2015). Processes of mineral trapping are slower than solubility trapping and occur over a longer (hundreds of years) geologic timescale (Bachu et al., 2015; Aminu et al., 2017). Such reactions enhance the spread of the dissolved $\mathrm{CO}_{2}$ and increase the safety of geological storage. Thus, it is important to understand the impact of geochemical reaction between carbonic acid and the host rocks' to evaluate the ability of a reservoir in storing $\mathrm{CO}_{2}$ in the long-term stability (Islam et al., 2016a; Rochelle et al., 1999) . This topic has been discussed in the literature (Ennis-King and Paterson, 2007; Ghesmat et al., 2011; Ward et al., 2015). Recently, Babaei and Islam (2018) investigated the effect of convective-reactive $\mathrm{CO}_{2}$ dissolution taking into account the mass transfer with immobile water. Erfani et al. (2020) studied the signature of geochemistry on DDC of $\mathrm{CO}_{2}$ in sandstone rocks. They showed that geochemical reactions play a major role in the convective-diffusive flow of $\mathrm{CO}_{2}$. Strong interaction between geochemical and DDC 
processes has been observed. Fu et al. (2015) demonstrated that the dissolution of carbonate rock initiates in regions of locally high mixing, but the geochemical reaction stops significantly earlier than the shutdown of convective mixing. Ghoshal et al. (2017) showed that the high dissolution rates intensify the fingering phenomenon. A significant issue here is the impact of the geochemical reactions on the hydraulic properties of the reservoir such as porosity and conductivity (Hidalgo et al., 2015). The importance of this process depends on the geological characteristics of rocks.

The coupled processes of DDC and mineral dissolution/precipitation can be affected by ambient rocks. Heterogeneity has been found to play a major role in controlling the DDCdissolution processes of $\mathrm{CO}_{2}$. Heterogeneity impacts on convection-dissolution processes of $\mathrm{CO}_{2}$ have been the subject of several studies. For instance, Kong and Saar (Kong and Saar, 2013) investigated the effect of stochastic heterogeneity on DDC processes during the dissolution of $\mathrm{CO}_{2}$ in brine. Based on numerical experiments, Islam et al. (2016b) showed that DDC and dissolution processes are influenced primarily by the heterogeneity in grain size. Dai et al. (2018) investigated the effectiveness of the heterogeneity-induced trapping mechanism. Based on a site application, they showed that heterogeneity-assisted trapping has a greater areal extent for secure offshore $\mathrm{CO}_{2}$ storage than gravitational trapping. Fractured domains are a particular type of heterogeneity. Fractures can generate preferential flow pathways and may increase the possibility of $\mathrm{CO}_{2}$ leakage from the geological formation, which can cause significant ecological risks (Zhang et al., 2018). Several ecological consequences of $\mathrm{CO}_{2}$ leakage on marine ecosystems are discussed in Molari e al. (2018) and Borrero-Santiago et al. (2020). Fischer et al. (2016) investigated the effect of $\mathrm{CO}_{2}$ storage on groundwater. For instance, pressure increase below the caprock, due to $\mathrm{CO}_{2}$ injection, can generate a preferential flow through faults and fractures that may exist in the caprock formation (Fitts and Peters, 2013). Preferential flow through Fractures and faults can make 
increase the risk of leakage through abandoned wells (Huo and Gong, 2010). The ongoing project DETECT (https://geoenergy.hw.ac.uk/research/detect/) aims at evaluating the risk of $\mathrm{CO}_{2}$ leakage along fractures of the primary caprock. Thus, in principle, densely fractured geological formations are usually unsuitable for safe $\mathrm{CO}_{2}$ sequestration (Kim et al., 2019). However, fractures and faults can be observed in several storage reservoirs such as in Algeria, the Appalachian Basin and Montana in the USA, and Janggi site in South Korea (Kim et al., 2019; Raziperchikolaee et al., 2019,2020). In certain sites, fractures are stimulated, by hydraulic fracturing, in order to improve the storage capacity of saline aquifers (Iding and Ringrose, 2010; Middleton et al., 2014; Raziperchikolaee et al., 2013).

The effects of fractures on non-reactive DDC processes have been extensively investigated in the literature but not in the context of $\mathrm{CO}_{2}$ sequestration (Hirthe and Graf, 2015; Jafari Raad and Hassanzadeh, 2018; Shafabakhsh et al., 2019; Simmons et al., 2008). Recently, Kim et al. (2019) investigated the effect of fractures on convective mixing during $\mathrm{CO}_{2}$ sequestration, but they neglect reactive processes. However, several studies showed that fractures can affect the reaction processes (Chaudhuri et al., 2008; Liu et al., 2017). Thus, it is important to understand the role of fractures on coupled $\mathrm{CO}_{2}$ convective mixing and geochemical processes in order to evaluate and predict $\mathrm{CO}_{2}$ trapping mechanisms in fractured geological formations. To the best of our knowledge, this topic has not been investigated in the past. Thus, this work aims at developing a comprehensive study on the effects of various fracture configurations on coupled mineral dissolution and DDC processes. Our methodology is based on numerical modeling which is considered as the most suitable tool to understand $\mathrm{CO}_{2}$ trapping mechanism, from the economical and practical point of view ( $\mathrm{Li}$ and Jiang, 2017; Jafari Raad and Hassanzadeh, 2017; Soltanian et al., 2019). Conclusions learned from numerical models are helpful in enhancing our understanding of physical processes and in addressing current research questions related to $\mathrm{CO}_{2}$ geological sequestration. Thus, based 
on COMSOL Multiphysics, we develop a model that couple Darcy's law with mass transport equation under variable density, which is a function of dissolved $\mathrm{CO}_{2}$ concentration. The fractures are considered explicitly via the discrete fracture model available in COMSOL. We consider simplified kinetic dissolution reaction of carbonic acid and calcium carbonate as in Kim et al. (2019) and the references therein. The model is first applied on a hypothetical domain overlaid by the supercritical layer of $\mathrm{CO}_{2}$, under different configurations of fractures (Babaei and Islam, 2018; Kim et al., 2019). We evaluate the effect of fracture characteristics, topology, and density on the total $\mathrm{CO}_{2}$ flux entering the domain, which is used as a metric of the domain storage capacity. The problem of a synthetic reservoir with hypothetical fractured configurations is relevant in providing preliminary insight on the effect of fractures on $\mathrm{CO}_{2}$ convection-dissolution processes but can show varying degrees of geological realism. For more representative geology, we apply the numerical model on a large-scale outcrop of a volcanic basalt rock formation in Lebanon. Based on the outcrop analogy we evaluate the capacity of fractured volcanic basalt rocks in trapping $\mathrm{CO}_{2}$.

\section{Governing equations and conceptual and numerical models}

\subsection{Mathematical model}

After the injection of $\mathrm{CO}_{2}$ into an aquifer, the $\mathrm{CO}_{2}$-rich fluid at the caprock has a higher density than the native formation fluid; therefore, the $\mathrm{CO}_{2}$-rich water will promote carbonate dissolution in the domain. The experiments on carbonate rock samples (Elkhoury et al., 2013) have indicated that the interaction between the $\mathrm{CO}_{2}$ solution and rocks results in the formation of carbonate minerals through a series of geochemical reactions. These mechanisms depend on the pressure, temperature, acidity, chemical composition of the brine, and the mineralogy of the rocks (Matter et al. 2007). The precipitation of Ankerite depends on the rate of 
reduction of mineral precursors such as goethite (Xu et al. 2004). In this work, we only focus on calcium carbonate dissolution.

The chemical system of the aqueous phase reactions and mineral-fluid reactions are summarized by the following chemical reactions. These reactions include acidification and carbonation of the native formation and potential mineral dissolution (Ghoshal et al., 2017; Izgec et al., 2005; Marini, 2006).

$$
\begin{gathered}
\mathrm{CO}_{2(\mathrm{aq})}+\mathrm{H}_{2} \mathrm{O} \longrightarrow \mathrm{H}_{2} \mathrm{CO}_{3(\mathrm{aq})} \\
\mathrm{H}_{2} \mathrm{CO}_{3(\mathrm{aq})} \longleftrightarrow \mathrm{H}_{(\mathrm{aq})}^{+}+\mathrm{HCO}_{3(\mathrm{aq})}^{-} \\
\mathrm{CaCO}_{3(\mathrm{~s})} \longleftrightarrow \mathrm{Ca}_{(\mathrm{aq})}^{2+}+\mathrm{CO}_{3(\mathrm{aq})}^{2-} \\
\mathrm{CaCO}_{3(\mathrm{~s})}+\mathrm{H}_{(\mathrm{aq})}^{+} \longleftrightarrow \mathrm{Ca}_{(\mathrm{aq})}^{2+}+\mathrm{HCO}_{3(\mathrm{aq})}^{-}
\end{gathered}
$$

The reactions above can be combined into the following main geochemical reaction:

$$
\mathrm{CO}_{2(\mathrm{aq})}+\mathrm{CaCO}_{3(\mathrm{~s})}+\mathrm{H}_{2} \mathrm{O} \longleftrightarrow \mathrm{Ca}\left(\mathrm{HCO}_{3}\right)_{2}
$$

Among the reactive species in the chemical system, $\mathrm{CO}_{2}(\mathrm{aq})$ and calcium carbonate $\left(\mathrm{CaCO}_{3}(\mathrm{~s})\right)$ are selected as primary species (Babaei and Islam, 2018).

Reactive natural convection of dissolved $\mathrm{CO}_{2}$ into the water in the porous matrix is governed by variable-density flow and mass transport equations. The mass conservation is ensured by the continuity equation and the velocity based on Darcy's law as follows:

$$
\begin{aligned}
& \varepsilon_{m} \frac{\partial \rho}{\partial t}+\nabla \cdot(\rho \boldsymbol{u})=0 \\
& \boldsymbol{u}=-\frac{k_{m}}{\mu}(\nabla p-\rho \boldsymbol{g})
\end{aligned}
$$

Where $\varepsilon_{m}$ is the porosity of the medium [-], $\rho$ is the mixed fluid density $\left[\mathrm{ML}^{-3}\right], t$ is the time $[\mathrm{T}], \boldsymbol{u}$ is the velocity $\left[\mathrm{LT}^{-1}\right], k_{m}$ is the intrinsic permeability of the porous matrix $\left[\mathrm{L}^{2}\right]$, 
$\mu$ is the fluid dynamic viscosity $\left[\mathrm{ML}^{-1} \mathrm{~T}^{-1}\right], p$ is the pressure $\left[\mathrm{ML}^{-1} \mathrm{~T}^{-2}\right]$, and $g$ is the gravity $\left[\mathrm{LT}^{-2}\right]$.

The convection-diffusion equation coupled to geochemical reactions for each chemical species in a non-deformable porous medium is as the following mass balance equations:

$$
\begin{gathered}
\varepsilon_{m} \frac{\partial c_{\mathrm{CO}_{2}}}{\partial t}+\nabla \cdot\left(\boldsymbol{u} c_{\mathrm{CO}_{2}}-\varepsilon_{m} D_{m} \nabla c_{\mathrm{CO}_{2}}\right)=r_{\text {chem }, \mathrm{CO}_{2}} \\
\varepsilon_{m} \frac{\partial c_{\mathrm{CaCO}_{3}}}{\partial t}=r_{\text {chem }, \mathrm{CaCO}_{3}}
\end{gathered}
$$

Where $c_{\mathrm{CO} 2}$ and $c_{\mathrm{CACO} 3}$ are the solute concentration $\left[\mathrm{ML}^{-3}\right]$, and $r_{\text {chem,CO2 }}$ and $r_{\text {chem,Сасо3 }}$ are the reaction terms $\left[\mathrm{ML}^{-3} \mathrm{~T}^{-1}\right]$ for $\mathrm{CO}_{2}$ and $\mathrm{CaCO}_{3}$, respectively. For these two species, the reaction terms which are assumed to be second-order can be written as (Babaei and Islam, 2018; Ghesmat et al., 2011):

$$
\begin{gathered}
r_{\text {chem }, \mathrm{CO}_{2}}=-k_{r} a_{v} c_{\mathrm{CO}_{2}}\left(c_{\mathrm{CaCO}_{3}}\right)^{n} \\
r_{\text {chem, } \mathrm{CaCO} \mathrm{C}_{3}}=-\varepsilon_{m} k_{r} a_{v} c_{\mathrm{CO}_{2}}\left(c_{\mathrm{CaCO}_{3}}\right)^{n}
\end{gathered}
$$

Where $k_{r}$ is the reaction rate constant $\left[\mathrm{L}^{4} \mathrm{M}^{-1} \mathrm{~T}^{-1}\right], a_{v}$ is the mineral surface area available for reaction per volume of the medium $\left[\mathrm{L}^{-1}\right]$, and $n$ is the rate of the reaction which is equal to 1 for the second-order reaction (Brezonik, 2018).

Finally, Equations (3), (4) and (5) are coupled with Boussinesq approximation by a linear function which relates the density $(\rho)$ and the concentration of $\mathrm{CO}_{2}\left(c_{\mathrm{CO} 2}\right)$ as follows:

$$
\begin{gathered}
\rho=\rho_{0}\left[1+\beta\left(c_{\mathrm{CO}_{2}}-c_{\text {initial } \mathrm{CO}_{2}}\right)\right] \\
\beta=\frac{1}{\rho_{0}}\left(\frac{\partial \rho}{\partial c_{\mathrm{CO}_{2}}}\right)
\end{gathered}
$$


Where $\rho_{0}$ is the density of fresh-water $\left[\mathrm{ML}^{-3}\right], \beta$ is the volumetric expansion coefficient in respect to the concentration of dissolved $\mathrm{CO}_{2}$. We assumed the effect of $\mathrm{CO}_{2}$ on the density of water is linear and $\beta>0$.

To generalize the results and characterize the mixing convection, allowing its comparison and application to different scales and conditions, we use the following dimensionless quantities to obtain the dimensionless form of governing equations.

$$
\begin{aligned}
& x^{*}=\frac{x}{H}, y^{*}=\frac{y}{H}, t^{*}=\frac{D_{m} t}{H^{2}} \\
& u^{*}=\left(u_{x}^{*}, u_{y}^{*}\right)=\left(\frac{H u_{x}}{\varepsilon_{m} D_{m}}, \frac{H u_{y}}{\varepsilon_{m} D_{m}}\right), P^{*}=\frac{k_{m}}{\varepsilon_{m} D_{m} \mu} P \\
& c_{\mathrm{CO} 2}^{*}=\frac{c_{\mathrm{CO} 2}-c_{\text {initial } \mathrm{CO} 2}}{c_{\text {Max } \mathrm{CO} 2}-c_{\text {initial } \mathrm{CO} 2}}, c_{\mathrm{CaCO} 3}^{*}=\frac{c_{\mathrm{CaCO} 3}^{*}}{c_{\text {nitial } \mathrm{CaCO} 3}^{*}}
\end{aligned}
$$

Applying the above change of variables gives the following dimensionless governing equations. Eq. (11) represent the mass conservation and Eq. (12) is for the convectiondiffusion equation coupled with reaction.

$$
\begin{gathered}
u^{*}=-\nabla^{*} P^{*}-R a \cdot c^{*} \\
\frac{\partial c_{\mathrm{CO} 2}^{*}}{\partial t^{*}}+\nabla^{*} \cdot\left(u^{*} c^{*}-\nabla^{*} c^{*}\right)+D a \cdot c_{\mathrm{CO} 2}^{*} \cdot c_{\mathrm{CaCO} 3}^{*}=0 \\
\frac{\partial c_{\mathrm{CaCO} 3}^{*}}{\partial t^{*}}+D a \cdot \varepsilon_{m} \cdot c_{\mathrm{CO} 2}^{*} \cdot c_{\mathrm{CaCO} 3}^{*}=0
\end{gathered}
$$

Where $R a$ and $D a$ are dimensionless numbers known as Rayleigh number and Damköhler number, respectively.

The non-dimensional Raleigh number $(R a)$ relates the ratio of the buoyancy forces that drive flow to diffusive forces that dissipate it. This parameter governs the natural convection processes, and it is used to characterize the onset of free convection. $R a$ is defined by(Prasad and Simmons, 2003): 


$$
R a=\frac{k_{m}\left(\rho_{s}-\rho_{0}\right) g H}{\mu \varepsilon D}
$$

In this work, $R a$ is defined using the permeability of the porous matrix $\left(k_{m}\right)$.

The dimensionless Damköhler number $(D a)$ expresses the strength of geochemical reactions in porous media, and it is defined as the ratio between reaction and diffusion rates. We use this parameter to characterize the reactivity in the model. A high $D a$ indicates a system with high reactivity due to the occurrence of fast reactions. In contrast, a low $D a$ means the chemical reaction is sufficiently slow as if no reactions were present; therefore, convective mixing could not occur (Babaei and Islam, 2018; Fu et al., 2015; Sainz-Garcia et al., 2017). Using the definition presented by (Ghesmat et al., 2011) for the second-order reaction over convection, $D a$ can be written as follows:

$$
D a=\frac{k_{r} a_{v} H^{2}}{\varepsilon D \cdot \Delta c}
$$

\subsection{Conceptual and numerical models}

The domain and boundary conditions of a two-dimensional $1(\mathrm{~m}) \times 1(\mathrm{~m})$ hypothetical reservoir are similar to the work of (Kim et al., 2019) and are shown in Fig. 1. In this reservoir, there is an initial concentration of Calcium Carbonate $\left(\mathrm{CaCO}_{3}\right)$ dissolution as an initial condition. At the top surface, there is a dissolved $\mathrm{CO}_{2}$ layer overlaying the domain with sinusoidal perturbation to initiate downward propagation of the dissolved $\mathrm{CO}_{2}$ fingers and to trigger instability. This perturbation is equal to $C_{C O 2}=1+A \cdot \sin (2 \pi x / \lambda)$, where $A$ is amplitude and $\lambda$ is the wavelength of the sinusoidal perturbation with the values of 0.01 and 1/12 respectively similar to (Kim et al., 2019). The lateral boundaries are considered to have periodic boundary conditions regarding the limitation of using a small domain size (Martinez and Hesse, 2016). The bottom boundary is assumed to be impermeable. The physical parameters used in this work are summarized in Table 1. 


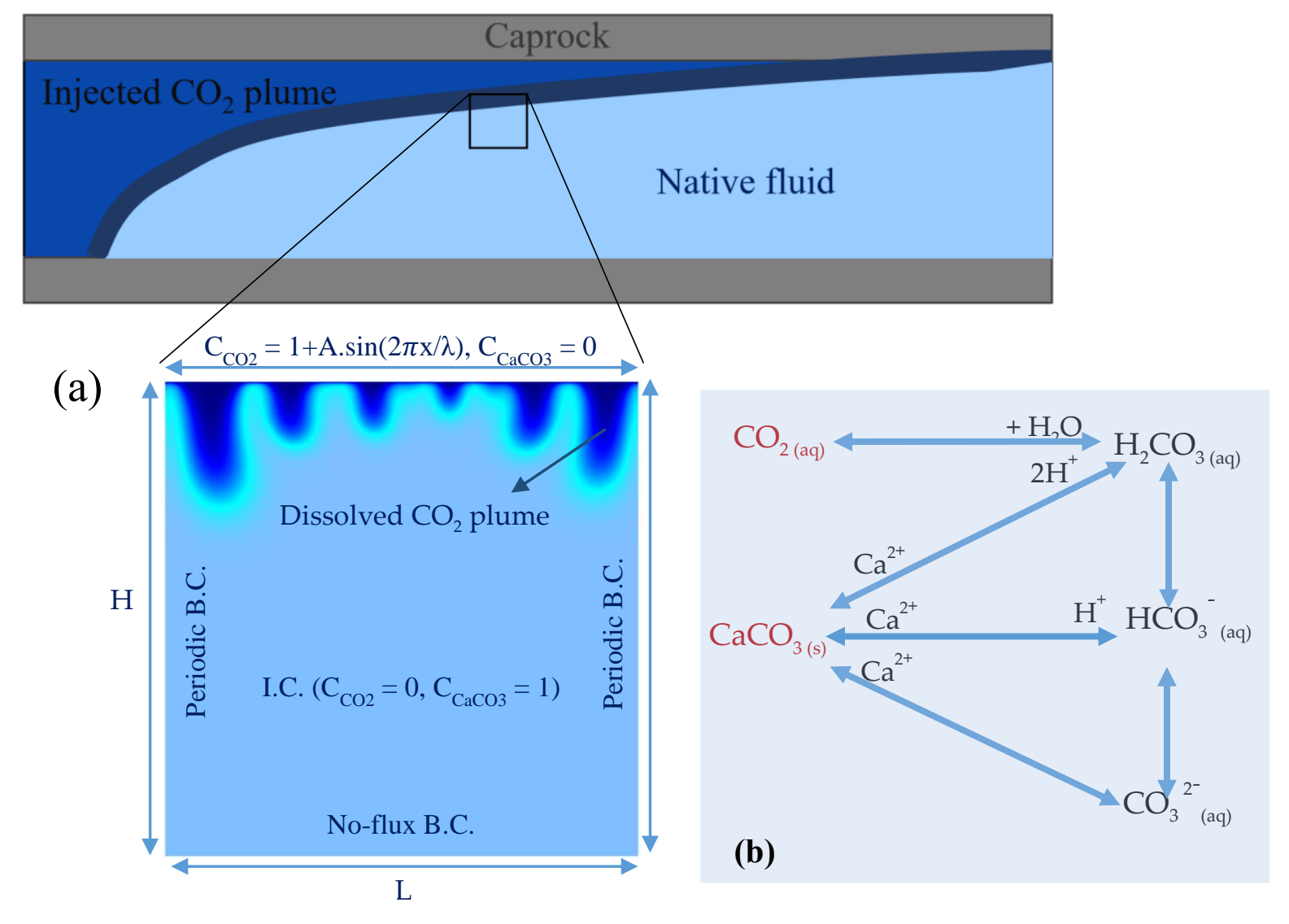

Fig.2. (a) Model domain with initial and boundary conditions. (b) The chemical system of the injected $\mathrm{CO}_{2}$ in the domain. 
Table 1. Physical parameters used in COMSOL.

\begin{tabular}{ccc}
\hline Parameter & Variable & Value \\
Length & $L$ & $1(\mathrm{~m})$ \\
Height & $H$ & $1(\mathrm{~m})$ \\
Density of fresh-water & $\rho_{0}$ & $1000\left(\mathrm{~kg} / \mathrm{m}^{3}\right)$ \\
Density of $\mathrm{CO}_{2}$-water at the top boundary & $\rho_{s}$ & $1010\left(\mathrm{~kg} / \mathrm{m}^{3}\right)$ \\
Concentration at the top boundary & $c_{b}$ & $1+A . \sin (2 \pi x / \lambda)$ \\
Amplitude of sinusoidal perturbation & $A$ & 0.01 \\
Wavelength of sinusoidal perturbation & $\lambda$ & $1 / 12(\mathrm{~m})$ \\
Porosity of the medium & $\varepsilon_{m}$ & 0.3 \\
Diffusion coefficient & $D_{m}$ & $1 \times 10^{-9}\left(\mathrm{~m}^{2} / \mathrm{s}\right)$ \\
Dynamic viscosity & $\mu$ & $5 \times 10^{-4}(\mathrm{~kg} /(\mathrm{m} \cdot \mathrm{s}))$ \\
Gravitational acceleration & $g$ & $9.8\left(\mathrm{~m} / \mathrm{s}^{2}\right)$ \\
Pressure at the top boundary & $P_{b}$ & $10(\mathrm{MPa})$ \\
Intrinsic permeability of the medium ${ }^{1}$ & $k_{m}$ & $3.8 \times 10^{-13}: 6.1 \times 10^{-12}\left(\mathrm{~m}^{2}\right)$ \\
Intrinsic permeability of fracture ${ }^{1}$ & $k_{f}$ & $\mathrm{k}_{\mathrm{m}} / 1000$ \\
Rate of reaction ${ }^{2}$ & $k_{r} a_{v}$ & $0: 3 \times 10^{-7}\left(\mathrm{~m}^{3} /\left(\mathrm{s} . \mathrm{mol}^{2}\right)\right)$ \\
Fracture length & $L_{f}$ & $0.8(\mathrm{~m})$ \\
Porosity of fracture & $\varepsilon_{f}$ & 0.5 \\
Fracture aperture & $2 b$ & $0.002(\mathrm{~m})$ \\
\hline
\end{tabular}

${ }^{1}$ Range of variation based on $R a$

${ }^{2}$ Range of variation based on $D a$

In this study, we investigated scenarios including single fractures with different positions and angles, and also networks of orthogonal fractures. By varying the Rayleigh number and Damköhler number, there are 72 fracture cases (18 cases for each scenario), as summarized in Table 2. 
Table 2. Simulation cases of fractured scenarios.

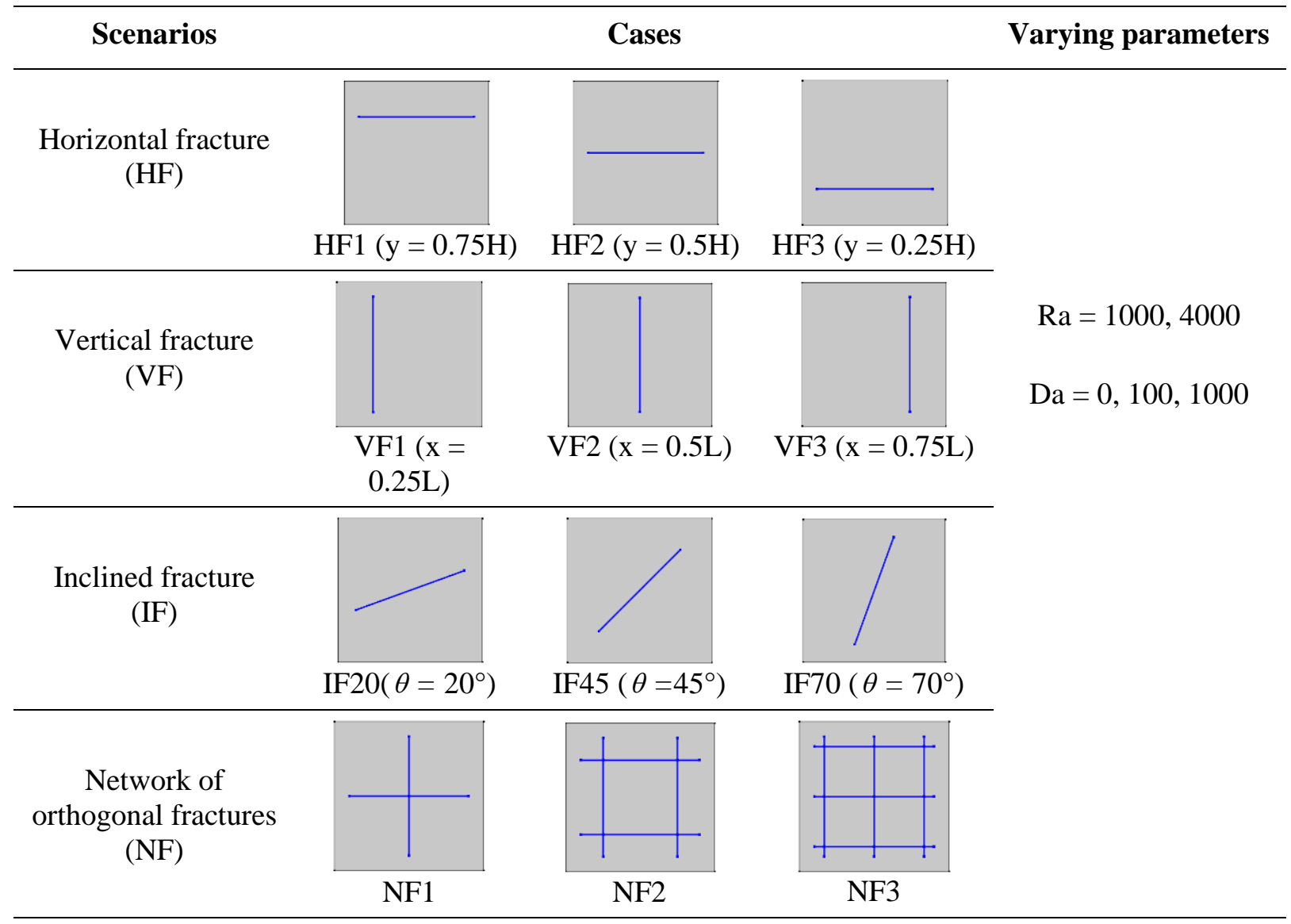

COMSOL Multiphysics (COMSOL, Inc., Palo Alto, CA, USA), which is a commercial finite element simulation package, was used in this work to perform the numerical simulations. To simulate the convective-reactive transport, we coupled the "Darcy's flow" interface from the "Subsurface flow" module and the "transport of diluted species in porous media" interface from the "chemical species transport" model. Since there are two primary chemical components $\left(\mathrm{CO}_{2}\right.$ and $\left.\mathrm{CaCO}_{3}\right)$ reacting in the model, we added separate "transport of diluted species in porous media" interface for each species. For $\mathrm{CaCO} 3$, we drop the convection and diffusion operators. The kinetic dissolution reactions are included as source terms in the transport equations. To include fractures via the discrete fracture approach (1D), we used the interface "Fracture flow" as in (Koohbor et al., 2019; Mozafari et al., 2018; Shafabakhsh et 
al., 2019). The system of flow and transport equations are solved simultaneously using the fully coupled approach in COMSOL. This leads to more expensive simulations in terms of CPU time but allows for avoiding numerical errors related to the operator splitting approach.

\section{Results and Discussion}

We considered the fractured scenarios described in Table 2. We examined reactive and nonreactive cases for each scenario and compared them with the homogeneous case (base case) in different combinations of convective flow (as different $R a$ ) and rate of chemical dissolution (as different $D a$ ). As presented in Table 2, in this study, $\mathrm{Ra}=1000$ and 4000 are referred to as medium and high convective flow; and $\mathrm{Da}=0,100$, and 1000 are referred to as non-reactive, slow-reactive, and fast-reactive respectively.

Total mass flux of $\mathrm{CO}_{2}$ at the top boundary entering in the domain $\left(T F_{t o p}\right)$ is a measurable characteristic that is used in this study to quantify the simulation results. The non-dimensional form of this parameter is defined as:

$$
T F_{\text {top }}^{*}=\frac{T F_{\text {top }} \times H}{\varepsilon_{m} D_{m} \Delta c}
$$

Which is known as Nusselt number (Ataie-Ashtiani et al., 2014) and defined as the ratio of the total mass flux through a upper layer and diffusive flux. It can be divided into two terms: The convective total flux, which is due to the advection process $\left(T F_{a d v, t o p}^{*}\right)$ and the total diffusive flux $\left(T F_{\text {diff, top }}^{*}\right)$. In addition, total mass flux of $\mathrm{CO}_{2}$ passing through the fracture $\left(T F_{f}\right)$ is another measurable characteristic in this work. The non-dimensional total flux through the fracture $\left(T F_{f}^{*}\right)$ has the same form as $T F^{*}$ top , and can be divided in convective ( $\left.T F_{a d v, f}^{*}\right)$ and diffusive $\left(T F_{d i f f, f}^{*}\right)$ total flux.

In what follows, we investigated each fractured scenario, and finally, we conduct a fieldscale exploration of density-driven convection in a deep geological formation. 


\subsection{Horizontal Fracture (HF)}

In this section, we examine horizontal fractured (HF) scenario and compare them with the homogeneous case (base case) in different values of $R a$ and $D a$. This scenario has three cases of different positions of horizontal fractures, as presented in Table 2. Fig. 2 represents this comparison by showing the dimensionless total flux of $\mathrm{CO}_{2}$ entering the domain from the top boundary $\left(\mathrm{TF}^{*}\right.$ top $)$ during a period of time, which is set to $t^{*}=0.015$ (the equivalent of 0.5 year) in this work. As expected in the bar charts, the values of $\mathrm{TF}^{*}{ }_{\text {top }}$ for reactive cases $(\mathrm{Da}$ $=100$ and 1000) are more than the non-reactive cases $(D a=0)$. The reason is that in reactive cases, there is dissolution of $\mathrm{CO}_{2}$ in reaction with $\mathrm{CaCO}_{3}$, and as a result of this dissolution, an increase in the gradient of $\mathrm{CO}_{2}$ concentration would appear at the top boundary, which causes an increase in the rate of entering total flux of $\mathrm{CO}_{2}$.

Considering $R a=1000$ (which represents having medium convective flow in this study) in Fig. 2(a), as one can observe, TF* ${ }_{\text {top }}$ of HF1 is lower than the base case for both non-reactive case $(D a=0)$ and slow-reactive case $(D a=100)$. This is because horizontal fractures in the domain play a restrictive role in entering of dissolved $\mathrm{CO}_{2}$. Also, we can see this concept in Fig. 2(a) in comparison of base case with HF2 and HF3 for these two amounts of $D a$, but in a lower difference because of the fact that the fracture in the cases of HF2 and HF3 are at middle and bottom of the domain respectively, and they have a lesser influence on the entering flux. As depicted in Fig. 3, which shows the concentration distribution of dissolved $\mathrm{CO}_{2}$ at $\mathrm{t}^{*}=0.01$ for different cases, for $\mathrm{Da}=0$ and 100 , it can be clearly seen that the fractures inhibit the growth of fingers. Therefore, there would be a lower amount of $\mathrm{CO}_{2}$ dissolution, and as a result, a lesser amount of flux enters the domain. Fig. 4 presents the variation of both convective and diffusive total fluxes at the top boundary versus $t^{*}$ for $R a=1000$ and $D a=0$ and 100 for the base case and HF1. First of all, by comparing the non-reactive $(D a=0)$ base case with HF1, for both convective and diffusive fluxes, it is shown that the base case has a 
higher amount of $\mathrm{TF}^{*}$ adv,top and $\mathrm{TF}^{*}{ }_{\text {diff,top }}$ during the period of time $\left(\mathrm{t}^{*}=0.015\right)$, and this confirms the restrictive role of fractures. However, in comparison of the reactive $(D a=100)$ base case with HF1, we see an opposite trend for diffusive flux after the first stage of mixing $\left(\mathrm{t}^{*}=0.0045\right)$, but for convective flux, we do not see any specific trend. (As shown in Fig. 3) Diffusion is dominant around edges and tips of the fingers, and existence of fracture helps the diffusion mechanism as it spreads dissolved $\mathrm{CO}_{2}$; therefore, in Fig. 4(b) $\mathrm{TF}^{*}$ diff,top for reactive $\mathrm{HF} 1$ is higher than reactive base case, and since the more $\mathrm{CO}_{2}$ dissolved in water, the more diffusive flux of $\mathrm{CO}_{2}$ enters from the top boundary readily. Nonetheless, comparison of reactive base case with HF1 in Fig. 4(a) reveals that while the fracture helps the mixing by convection and reaction processes, it inhibits the entrance flux of $\mathrm{CO}_{2}$, and it is why the trend of $\mathrm{TF}^{*}$ adv,top curves for these two cases are not like $\mathrm{TF}^{*}{ }_{\text {diff,top }}$ curves.

For medium $R a(=1000)$ with fast reaction $(D a=1000)$, as we have more $D a$, the rate of reaction is higher. By comparing the base case with the fractured cases for $D a=1000$ in Fig. 2(a), we see $\mathrm{TF}^{*}$ top for fractured cases are higher than the base case. This is related to the existence of the fracture which can provide a place where the reaction process may occur, and therefore, more dissolution of $\mathrm{CO}_{2}$ leads to having more $\mathrm{TF}^{*}{ }_{\text {top }}$. To measure the amount of reaction in the domain, we can check the decrease of average concentration of $\mathrm{CaCO}_{3}$ (corresponds to the change of mass in the domain) to see the amount of dissolution of $\mathrm{CaCO}_{3}$ in reaction with $\mathrm{CO}_{2}$. Fig. 5 illustrates the variation of the average concentration of $\mathrm{CaCO}_{3}$ for the slow and fast reactive cases. In this figure, we can see that the difference between the cases starts from the first stage of mixing $\left(t^{*}=0.0045\right)$, and it is obvious that for medium $R a$ $(=1000)$ when there is a low reaction rate $(D a=100)$ in the domain, the base case has more dissolution due to having more entering $\mathrm{TF}_{\text {top }}$ of $\mathrm{CO}_{2}$ rather than the fracture cases. But when there is a high reaction rate $(D a=1000)$ in the domain, the fracture cases have more dissolution than the base case because of having a place (fractures), which helps the reaction 
process. To illustrate the development of fingers of dissolved $\mathrm{CO}_{2}$, in Fig. 3 it is perfectly evident that for fast reaction cases $(D a=1000)$, the fracture helps the dissolution process through the fracture (specifically in HF1 and HF2 at $t^{*}=0.01$ when fingers reach the fracture), and for slow reaction cases $(D a=100)$, longer fingers can be seen in reactive base case which leads to having more dissolution rather than HF cases. In brief, for medium $R a$, when there is a slow reaction, the existence of horizontal fracture causes the domain to capture the lower total flux of $\mathrm{CO}_{2}$. Also, when there is a fast reaction, the horizontal fracture causes the domain to capture a higher amount of total flux of $\mathrm{CO}_{2}$.

In Fig. 2(b), we have high $R a(=4000)$, which represents a higher convective flow. Therefore, there is higher natural convection, and as it is shown the bar chart, regardless of the value of $D a, \mathrm{TF}^{*}$ top are almost the same due to convective mixing. However, there is a slight difference in non-reactive cases and the cases with low reaction. Thus, If the $R a$ is high, especially for fast reactions, the horizontal fractures will not affect our estimation of the total flux of $\mathrm{CO}_{2}$ that can be stored in the domain.
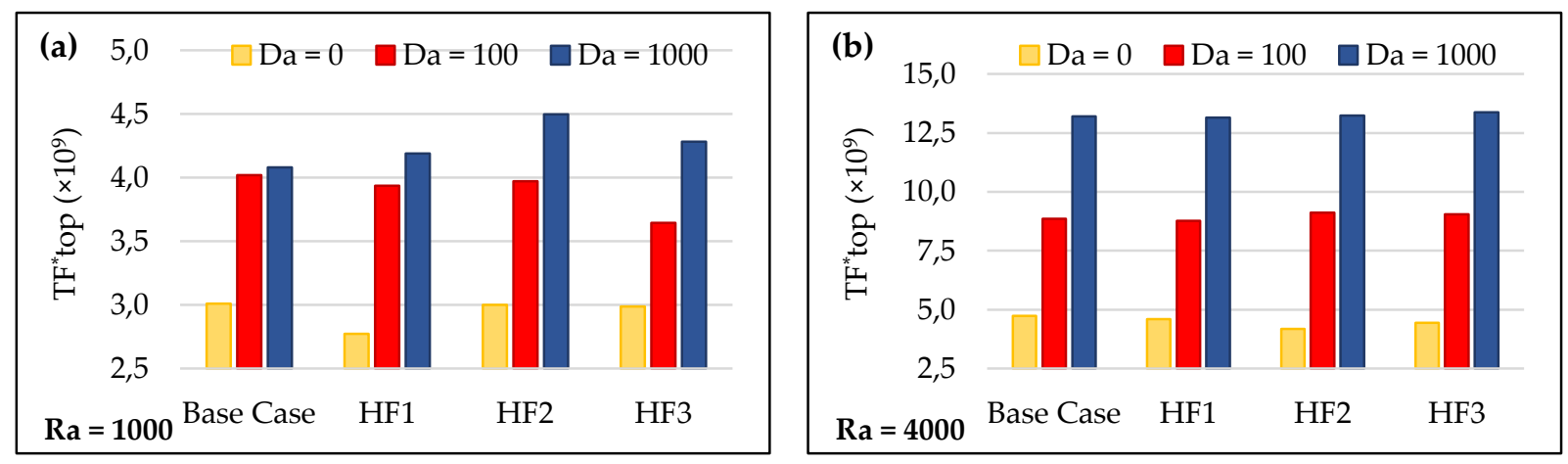

Fig. 3. Time integration of the dimensionless total flux of $\mathrm{CO}_{2}$ at the top boundary ( $\mathrm{TF}^{*}$ top) for both homogeneous unfractured case and horizontal fractured cases: medium convection flow $(\mathrm{Ra}=1000)$ at left and high convection flow $(\mathrm{Ra}=4000)$ at right. 


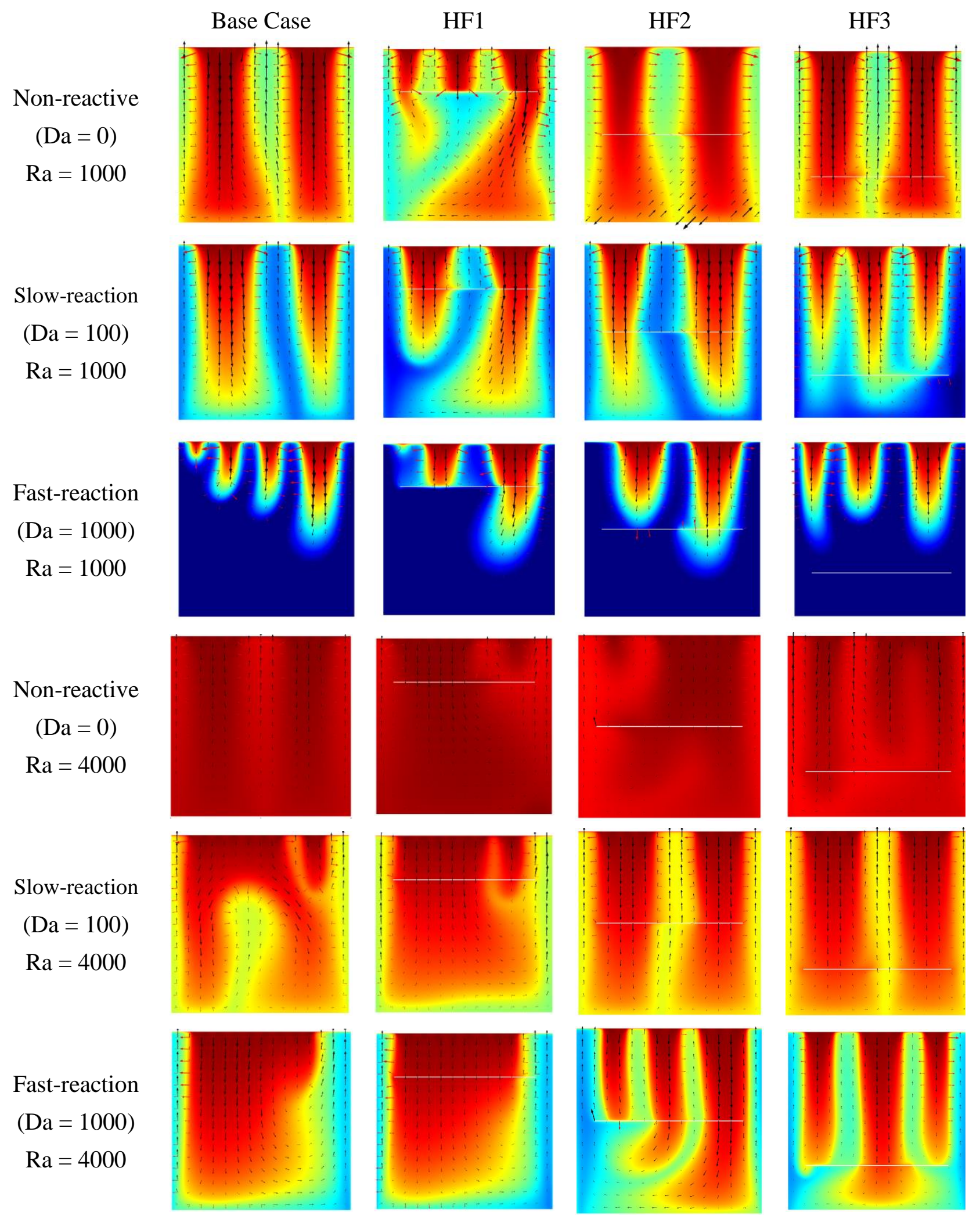

Fig. 4. Concentration distribution of dissolved $\mathrm{CO}_{2}$ for unfractured homogeneous and $\mathrm{HF}$ scenarios at $\mathrm{t}^{*}=0.01$. The black arrows and red arrows represent convective and diffusive fluxes respectively. 

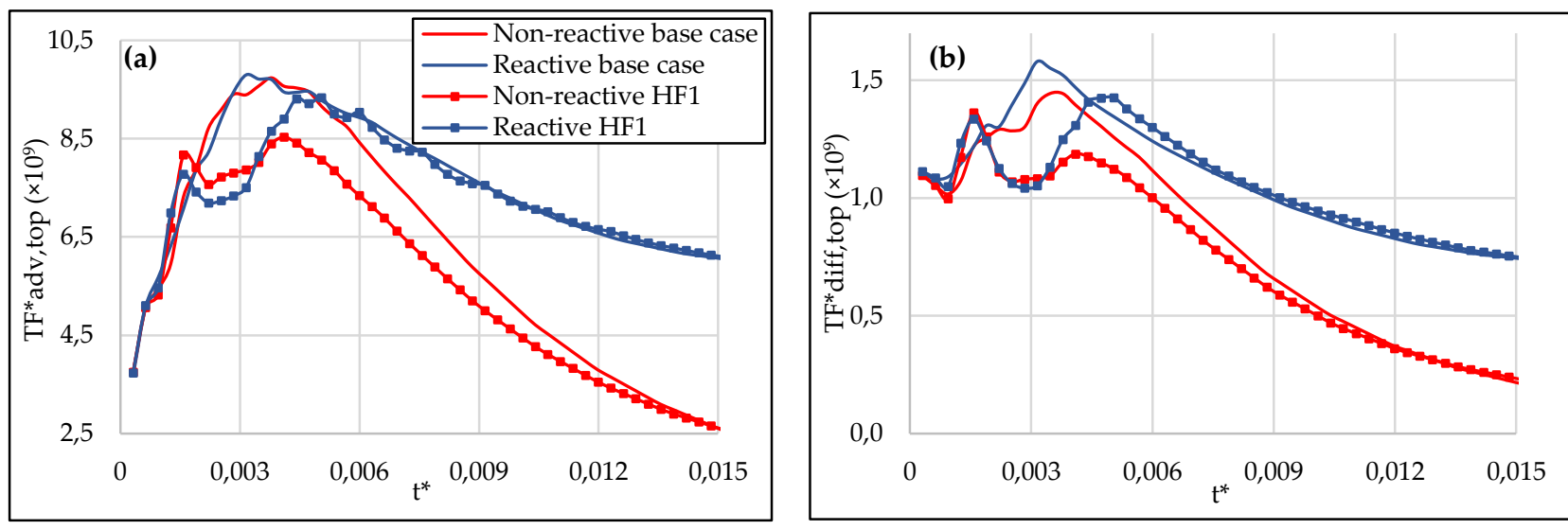

Fig. 5. Time variation of the dimensionless fluxes of $\mathrm{CO}_{2}$ at the top boundary for the $\mathrm{HF}$ scenario: (a) total convective flux and (b) total diffusive flux $(\mathrm{Ra}=1000$ and $\mathrm{Da}=0,100)$.
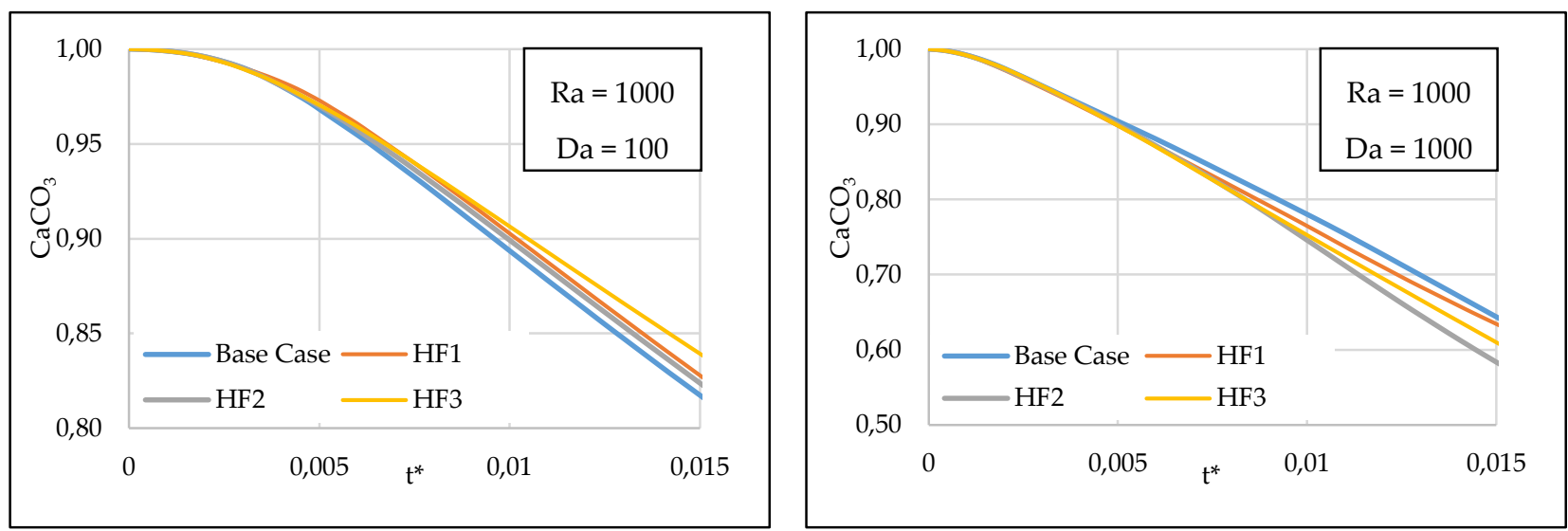

Fig. 6. Time variation of the average concentration of $\mathrm{CaCO}_{3}$ in the domain: low reaction rate (at left) and high reaction rate (at right), for the HF scenario.

\subsection{Vertical Fracture (VF)}

In the present section, we explore vertical fractured (VF) scenario for three cases of different positions of vertical fracture, as mentioned in Table 2 similar to the cases of HF scenario. Fig. 6 shows the results of the dimensionless total flux of $\mathrm{CO}_{2}$ entering the domain during $\mathrm{t}^{*}$ $=0.015$. To begin with, like the horizontal fracture, $\mathrm{TF}^{*}$ top for reactive cases are more than the non-reactive cases because of the reasons noted in the previous section. For medium $R a$ $(=1000)$ in Fig. 6(a) considering non-reactive cases $(D a=0)$, as one can observe, $\mathrm{TF}^{*}$ top of the base case is higher than the fractured cases. But for reactive cases ( $D a=100$ and 1000) 
it is vice versa, and especially when there is a fast dissolution $(D a=1000), \mathrm{TF}^{*}$ top of the base case is lower than the fractured cases. This can be related to the fact that for non-reactive cases, the presence of fracture seems to be an obstacle for the convective flow, and during mixing convection, because of the upward flow of freshwater through the vertical fracture (Kim et al., 2019), it would cause to be lower entering flux of dissolved $\mathrm{CO}_{2}$. Nonetheless, for reactive cases, the presence of fracture facilitates the reaction process and provides a location where the reaction can take place. As a result, there would be more precipitation of $\mathrm{CO}_{2}$ with minerals. This increases the concentration gradient and lead to more dissolved $\mathrm{CO}_{2}$ flux to enter from the top boundary. In Fig. 6(b), almost the same results of high $R a(=4000)$ are shown, and we see that the difference between the fractured cases and the base case for each $D a$ are not noticeable as medium $R a$ cases, because of the high natural mixing convection. Since the $\mathrm{CO}_{2}$ is injected sinusoidally through the top boundary, the coincide of dense plume flow with the fracture is by chance, and we cannot observe any relation between the different VF cases, as they have different positions and do not confront a determined plume of $\mathrm{CO}_{2}$.

Fig. 7 presents the concentration distribution of dissolved $\mathrm{CO}_{2}$ at $\mathrm{t}^{*}=0.01$ for the base case and VF scenario for non-reactive and reactive cases. For the non-reactive cases, the restrictive effect of the vertical fracture on the finger development is clear. For instance, in cases VF1 and VF3, we can see the fracture hinders the left and right fingers respectively to growth due to the upward flow of freshwater. As mentioned above, because of sinusoidal injected $\mathrm{CO}_{2}$, the plume flow through the fracture is accidental, and for example in Fig. 7 for VF1 when $D a=1000$, we can see the generation of a finger through the fracture, so it explains why in Fig. $6 \mathrm{a}, \mathrm{TF}^{*}$ top for VF1 at fast-reactive case, is higher than the other fractured cases.

Fig. 8 shows the variation of convective and diffusive total fluxes at the top boundary versus $\mathrm{t}^{*}$ at $R a=1000$ and at $D a=0$ and 100 for the base case and VF2. In both of the convective 
and diffusive total fluxes at the first stage of mixing $\left(t^{*}=0.006\right)$, we see a higher maximum of $\mathrm{TF}^{*}$ adv,top and $\mathrm{TF}^{*}$ diff,top for reactive and non-reactive cases of $\mathrm{VF} 2$, since the $\mathrm{CO}_{2}$ plumes migrate downward across the vertical fracture at this period. However, after the first stage of mixing for both of the convective and diffusive total fluxes, we see the same trend as horizontal fracture depicted in Fig. 4.
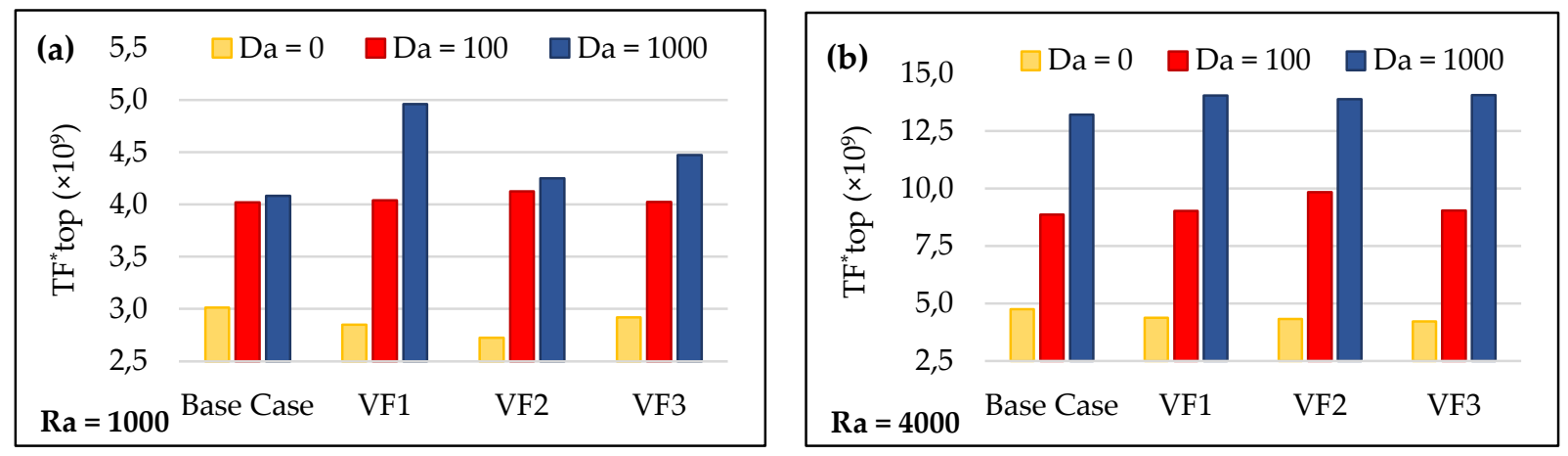

Fig. 7. Time integration of the dimensionless total flux of $\mathrm{CO}_{2}$ at the top boundary (TF* top) for the VF scenario: medium convection flow $(\mathrm{Ra}=1000)$ at left and high convection flow $(\mathrm{Ra}=4000)$ at right. 


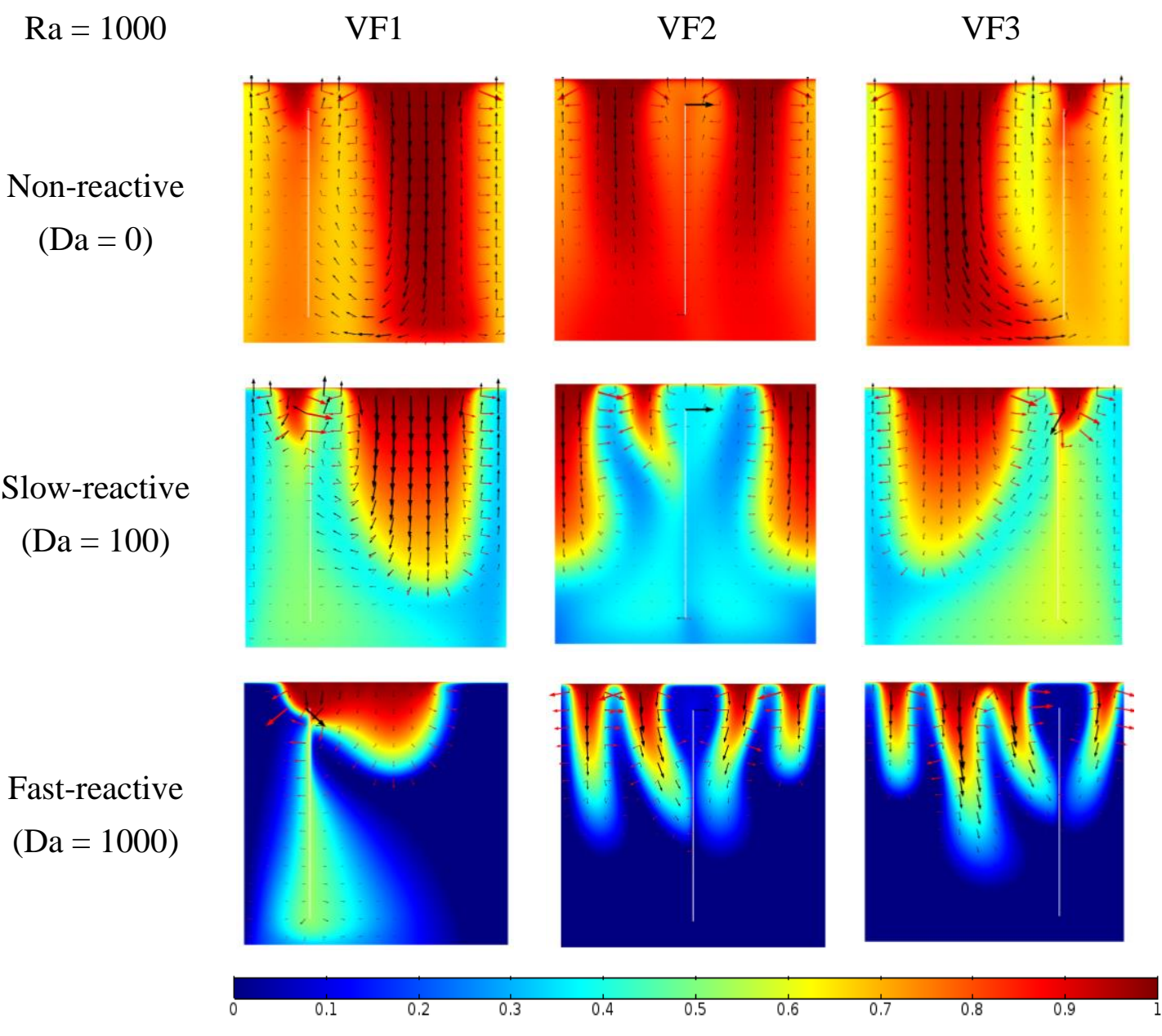

Fig. 8. Concentration distribution of dissolved $\mathrm{CO}_{2}$ for homogeneous and VF scenario at $\mathrm{t}^{*}=$ 0.01. In all cases $R a=1000$. The black arrows and red arrows represent convective flux and diffusive flux respectively.
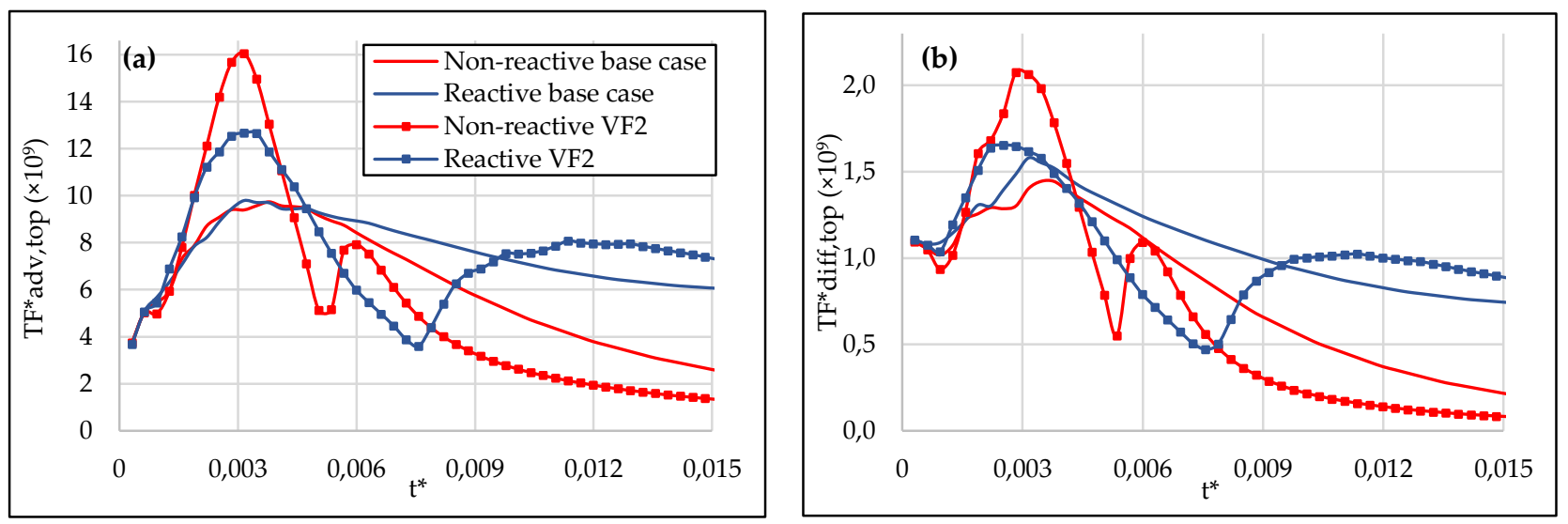

Fig. 9. Time variation of the dimensionless fluxes of $\mathrm{CO}_{2}$ at the top boundary for the VF scenario: (a) total convective flux and (b) total diffusive flux $(\mathrm{Ra}=1000$ and $\mathrm{Da}=0,100)$. 


\subsection{Inclined Fracture (IF)}

This section considers the inclined fractured scenario for three different cases. It examines the effect of fracture angle on the dissolution of injected $\mathrm{CO}_{2}$ in reactive porous media for low angle $\left(20^{\circ}\right)$, medium angle $\left(45^{\circ}\right)$, and high angle $\left(70^{\circ}\right)$ fracture. Fig. 9 represents the dimensionless total flux of $\mathrm{CO}_{2}$ entering the domain during $\mathrm{t}^{*}=0.015$. Comparing the base case and low angle case, we can see for medium $R a(=1000)$, no matter of the value of $D a$ (or the amount of rate of reaction), $\mathrm{TF}^{*}{ }_{\text {top }}$ of the base case is higher than $\mathrm{TF}^{*}$ top of IF20 case, and this is also true for high $R a(=4000)$ with lower intensity as there is higher convective mixture. This can be attributed to the fact that low angle fracture has almost the same features as a horizontal fracture; thus, it restricts the entering flow of dissolved $\mathrm{CO}_{2}$. Moreover, as depicted in Fig. 10, which shows the concentration distribution of dissolved $\mathrm{CO}_{2}$ at $\mathrm{t}^{*}=0.01$, for all $D a$ of the IF20 case, it is clear that the low angle fracture, like the horizontal fracture, inhibits the growth of fingers.

In Fig. 9(a), the case of high angle fracture (IF70) has the highest value of $\mathrm{TF}^{*}$ top in comparison with the other cases when there is a reaction in the domain (especially fast reaction). In this case, as depicted in Fig. 10, fracture helps the freshwater to transfer upward in the domain, and it causes the merging and mixture of the plume fingers of dissolved $\mathrm{CO}_{2}$ over the domain. By having a fast reaction, there is more dissolution of $\mathrm{CO}_{2}$; therefore, the total entering flux of $\mathrm{CO}_{2}$ increases. The case of medium angle fracture (IF45) seems to have a restrictive role for entering flow of dissolved $\mathrm{CO}_{2}$ and in addition to be a pathway for the upward flow of freshwater; thus, it has a combined feature of IF20 and IF70. For high $R a$ (= 4000) in Fig. 9(b), as noted before, a very slight difference can be seen between different cases, and they have almost the same value of $\mathrm{TF}^{*}$ top like other scenarios.

Figs. 11(a and b) show the variation of both convective and diffusive total fluxes at the top boundary versus $\mathrm{t}^{*}$ for $R a=1000$. First of all, in these two figures, it is clear that the fluxes 
of reactive cases are higher than the non-reactive cases after the first stage of mixing $\left(\mathrm{t}^{*}=\right.$ 0.006), and have the same trend as previous scenarios. In the first stage of mixing, as one can observe, high angle fracture case has the highest value (especially for convective flux), and low angle fracture case has the lowest value. The reason is that IF70 at the first stage is the pathway for dissolved $\mathrm{CO}_{2}$ and it facilitates the convective flow. However, IF20 at the first stage is like a horizontal fracture, and it inhibits the $\mathrm{CO}_{2}$ plumes. Figs. 11(c and d) show the variation of both convective and diffusive total fluxes through the fracture $\left(\mathrm{TF}^{*}\right.$ adv,, and $\left.\mathrm{TF}^{*}{ }_{\text {diff,f }}\right)$ versus $\mathrm{t}^{*}$ at $R a=1000$. Here also, we can see at the end of the mixing, the fluxes through the fracture of reactive cases are higher than the non-reactive cases because of the higher dissolution of $\mathrm{CO}_{2}$. In Fig. 11d for diffusive flux through the fracture, we see the same trend as the fluxes at the top boundary. However, in Fig. 11c due to the interaction between different tendencies of inclined fracture in restricting the growth of $\mathrm{CO}_{2}$ plumes, increasing mixing convection, and being a pathway for upward transport of freshwater, there is no particular trend for curves of convective flux through the fracture.
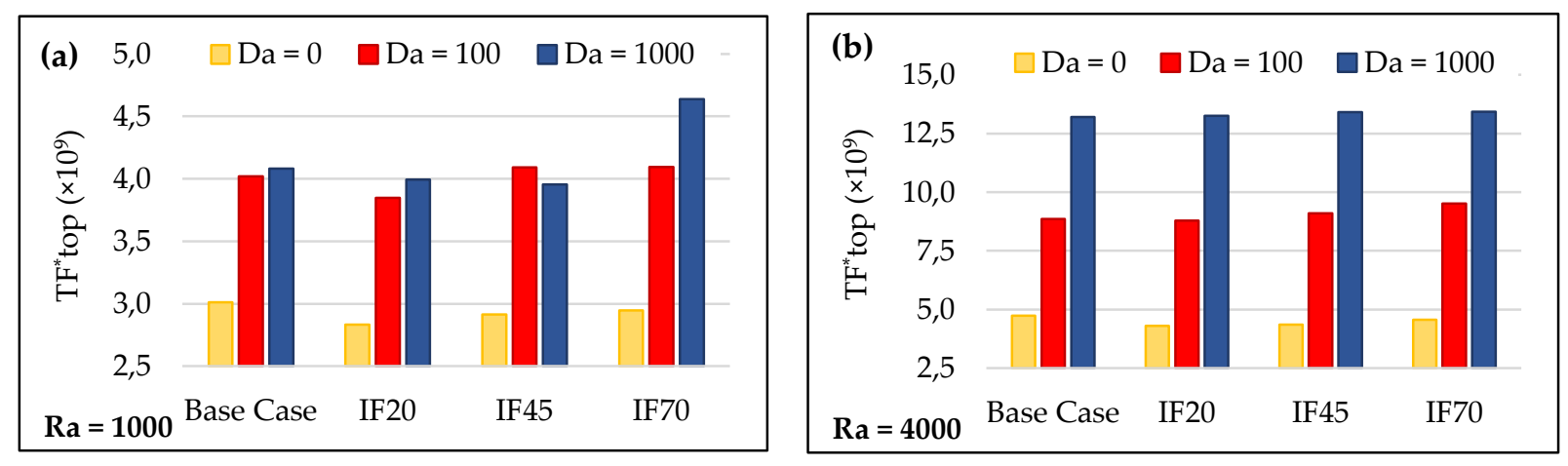

Fig. 10. Time integration of the dimensionless total flux of $\mathrm{CO}_{2}$ at the top boundary ( $\mathrm{TF}^{*}{ }_{\text {top }}$ ) for the inclined fractured scenario: medium convection flow $(\mathrm{Ra}=1000)$ at left and high convection flow $(\mathrm{Ra}=4000)$ at right. 


$$
\mathrm{Ra}=1000
$$

Non-reactive

$(\mathrm{Da}=0)$
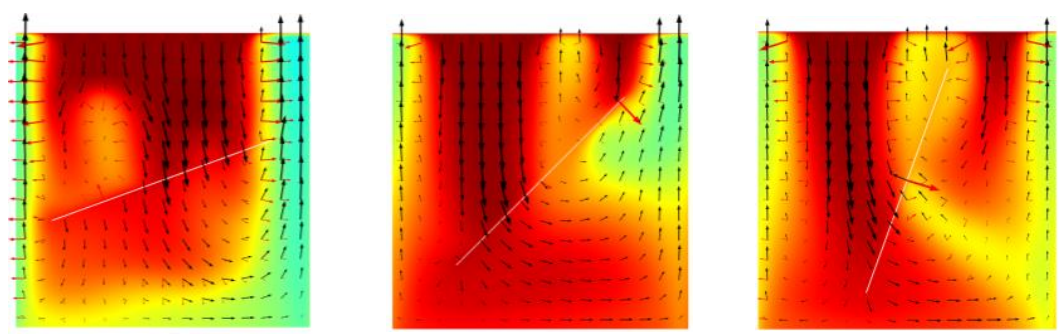

Slow-reactive

$(\mathrm{Da}=100)$
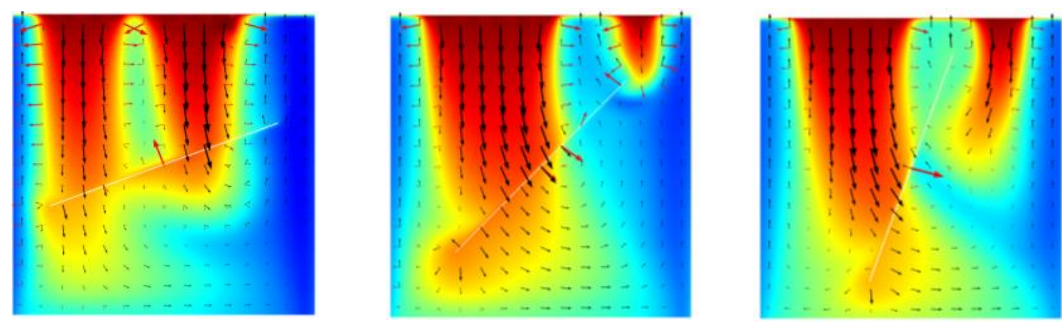

Fast-reactive $(\mathrm{Da}=1000)$
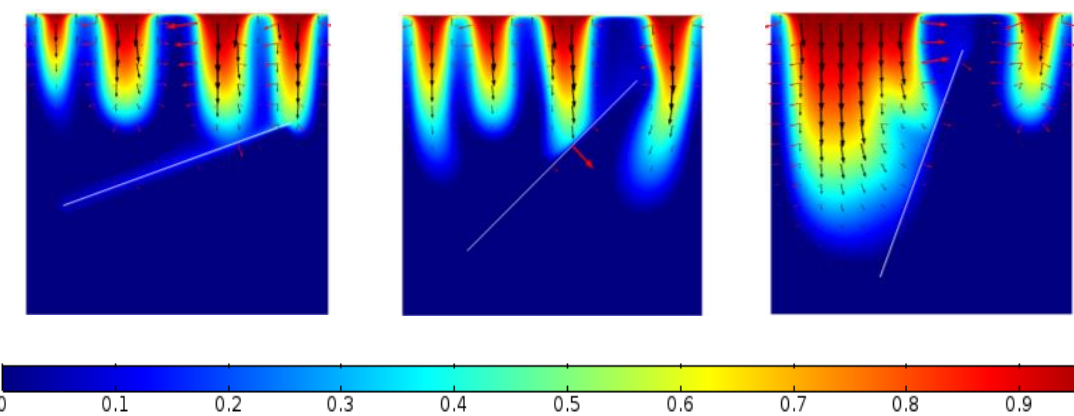

0.2 0.3 0.4 0.5 0.6 0.7 0.8 0.9

Fig. 11. Concentration distribution of dissolved $\mathrm{CO}_{2}$ for homogeneous and IF scenario at $\mathrm{t}^{*}$ $=0.01$. In all cases $R a=1000$. The black arrows and red arrows represent convective flux and diffusive flux respectively. 

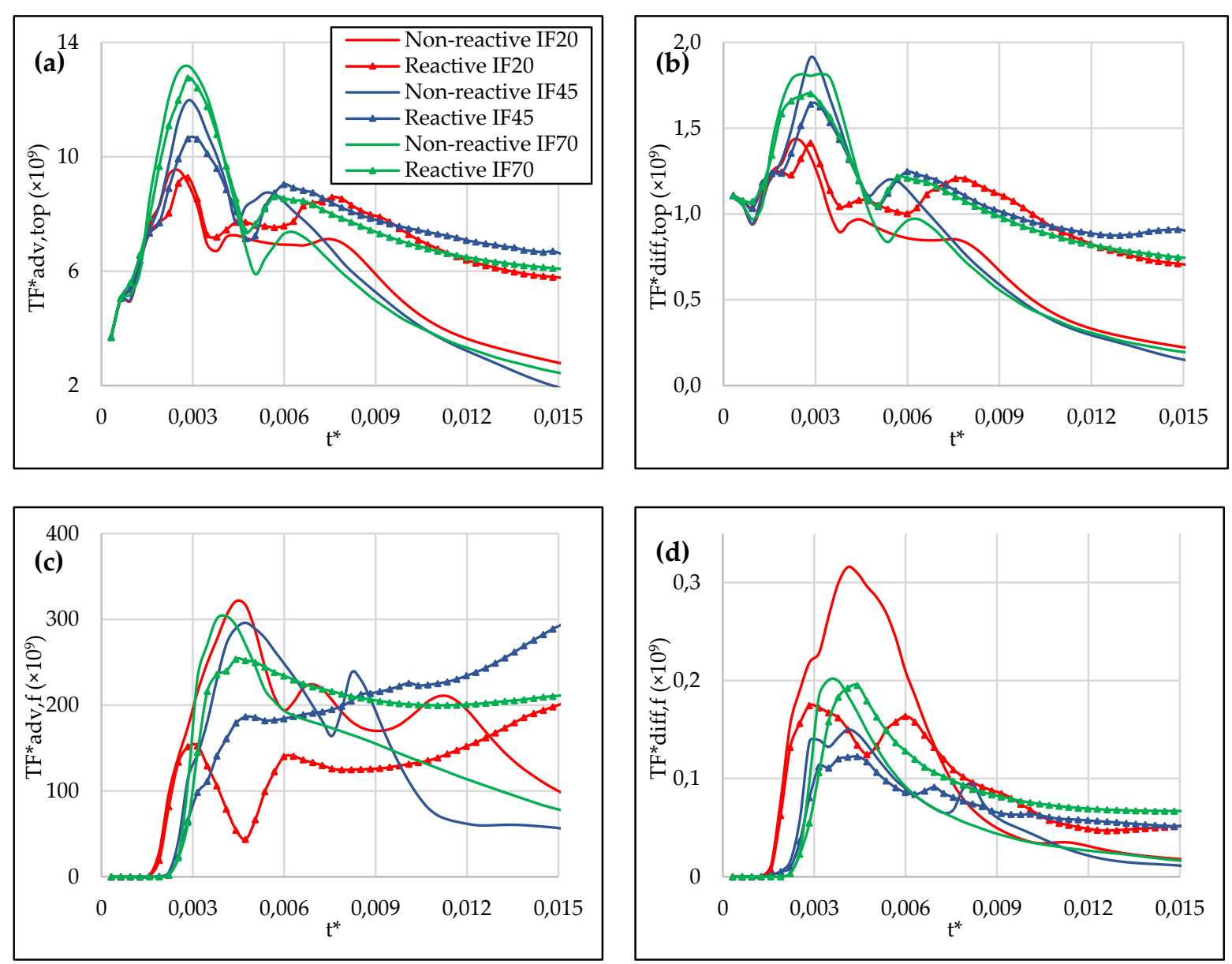

Fig. 12. Time variation of dimensionless convective total flux at the top boundary (a), diffusive total flux at the top boundary (b), convective total flux through the fracture (c), and diffusive total flux through the fracture (d).

\subsection{Network of Fractures (NF)}

The effect of different levels of fracture network (referred to as fracture density) on convective-reactive transport is investigated in this section. We consider three cases as three different levels of orthogonal fractures for the network of fracture (NF) scenario, as defined in Table 2. Like all the previous scenarios, the dimensionless total flux of $\mathrm{CO}_{2}$ entering the domain during $\mathrm{t}^{*}=0.015$ for different cases of NF scenario are represented in Fig. 12 . Comparing the base case with the cases of the NF scenario for medium convective flow ( $R a$ $=1000)$ in Fig. 12a, we can see that for the fast-reactive cases $(D a=1000)$ the total entering flux of dissolved $\mathrm{CO}_{2}$ from the top boundary are getting higher by increasing the level of the 
orthogonal fractures (fracture density), and this is noticeable even if for high $R a$ in Fig. $12 b$. The reason is that as the level of orthogonal fractures increase, there would be more fractures to help the mixing and to provide a place where the reaction process can occur, and more dissolution of $\mathrm{CO}_{2}$ leads to greater $\mathrm{TF}^{*}$ top. This is almost true for slow-reactive cases $(D a=$ 100) but in a lower intensity due to the lower dissolution. Fig. 13 shows the concentration distribution of dissolved $\mathrm{CO}_{2}$ at $\mathrm{t}^{*}=0.01$. It is clear for the reactive cases, increasing the level of fractures causes the plumes of dissolved $\mathrm{CO}_{2}$ to distribute over the domain, and we can see that the fractures behave as pathways that help the dissolution.

As noted before, to find out the amount of reaction occurring in the domain, we can measure the decrease in the average concentration of $\mathrm{CaCO}_{3}$. Fig. 14 presents the variation of the average concentration of $\mathrm{CaCO}_{3}$ in the domain for the different convective-reactive flow of NF scenario. Figs. 14(a and d) we have the lowest and highest loss of $\mathrm{CaCO}_{3}$ concentration respectively as expected, since for the first case, there is low reaction and medium natural convection, and for the second case, there is high reaction and high natural convection. As one can observe, only in Fig. $14 \mathrm{~b}$, in which $R a=1000$ and $D a=1000$, is there a noticeable difference between the curves of different cases, and for other combinations of $R a$ and $D a$ we cannot distinguish them easily. The case with slow reaction $(D a=100)$ does not have a large impact on the variation of $\mathrm{CaCO}_{3}$ concentration, since there is not enough dissolution of dissolved $\mathrm{CO}_{2}$ in reaction with $\mathrm{CaCO}_{3}$, and it can be confirmed by observing the lowreactive cases of Fig. 12. Furthermore, high natural convection $(R a=4000)$ leads to having more convective mixing, and as shown in Fig. 14 (c and d), different cases of NF scenario have almost the same amount of dissolution. In Fig. 14b as expected from the discussion above for the total entering flux of $\mathrm{CO}_{2}$, the loss of $\mathrm{CaCO}_{3}$ concentration for the cases NF2 and NF3 are more than NF1, and also it is more than the base case, and we can see the higher fracture density results in more mixing and consequently more reaction. 

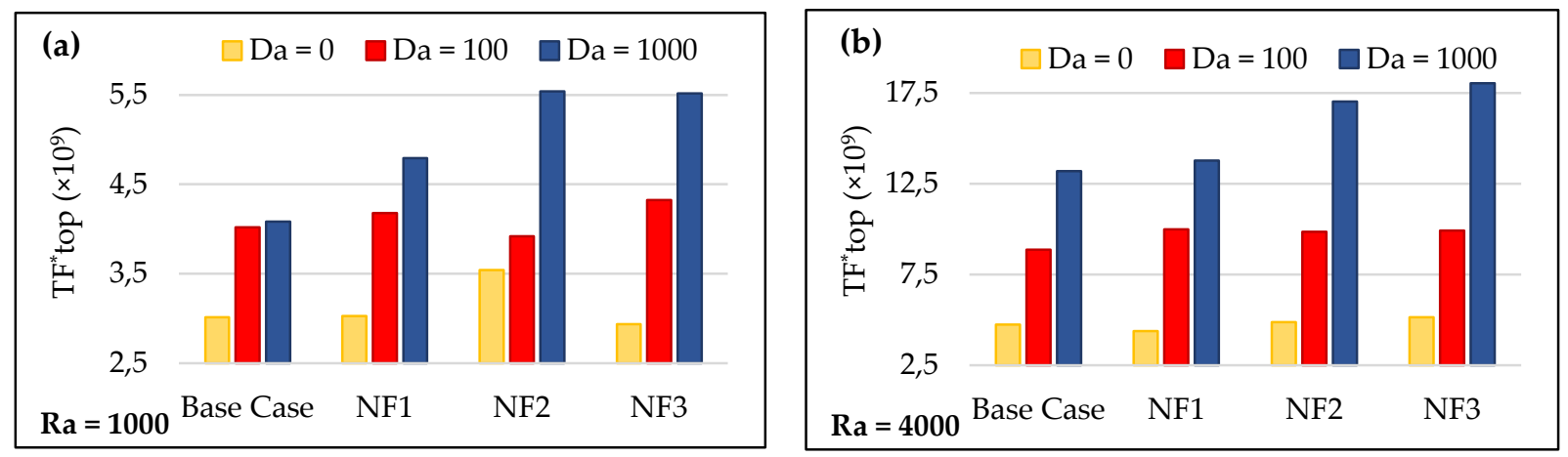

Fig. 13. Time integration of the dimensionless total flux of $\mathrm{CO}_{2}$ at the top boundary $\left(\mathrm{TF}^{*}\right.$ top $)$ for the network of fractures scenario: medium convection flow $(\mathrm{Ra}=1000)$ at left and high convection flow $(\mathrm{Ra}=4000)$ at right.

$$
\mathrm{Ra}=1000
$$

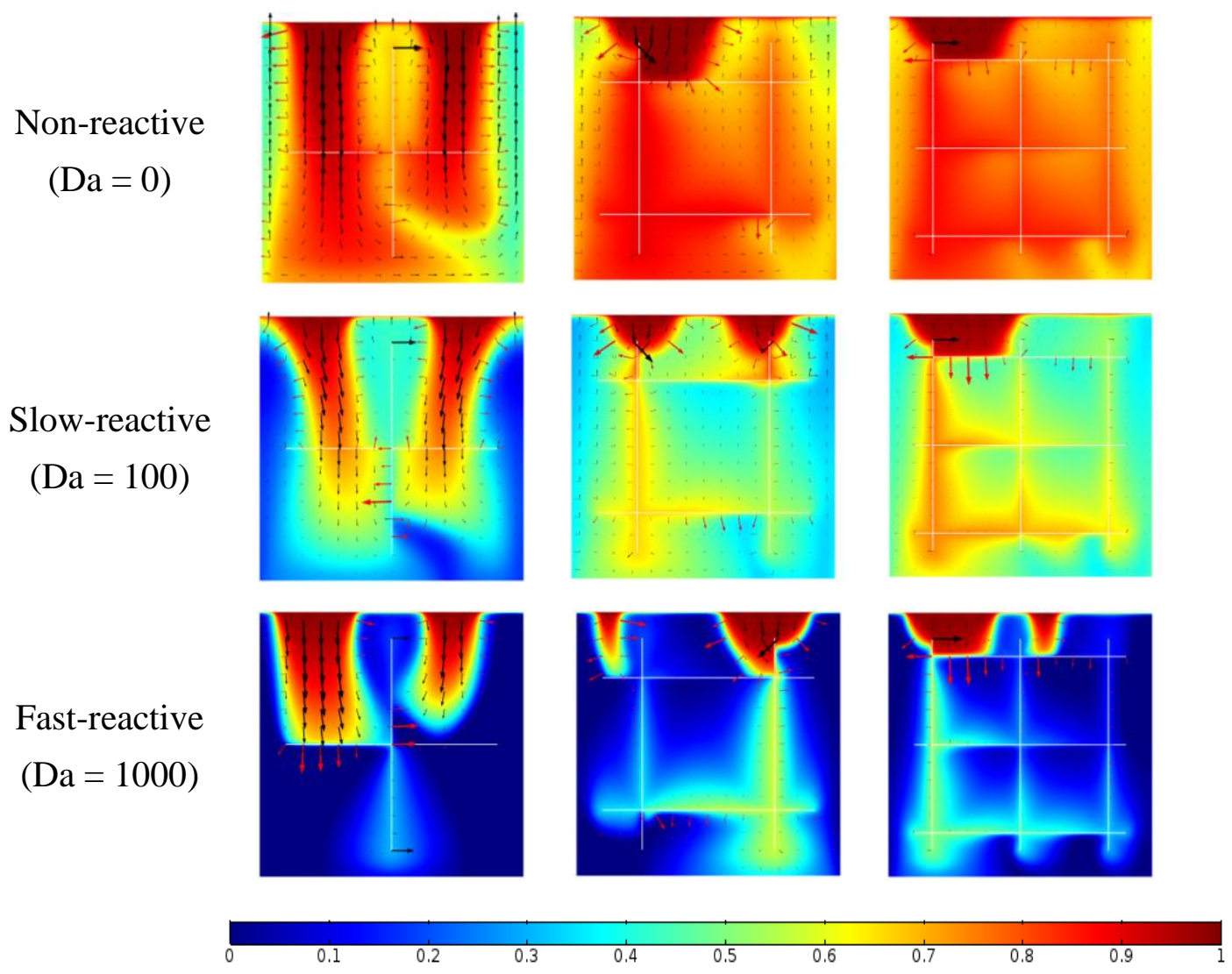

Fig. 14. Concentration distribution of dissolved $\mathrm{CO}_{2}$ for homogeneous and $\mathrm{NF}$ scenario at $\mathrm{t}^{*}=0.01$. In all cases $R a=1000$. The black arrows and red arrows represent convective flux and diffusive flux respectively. 

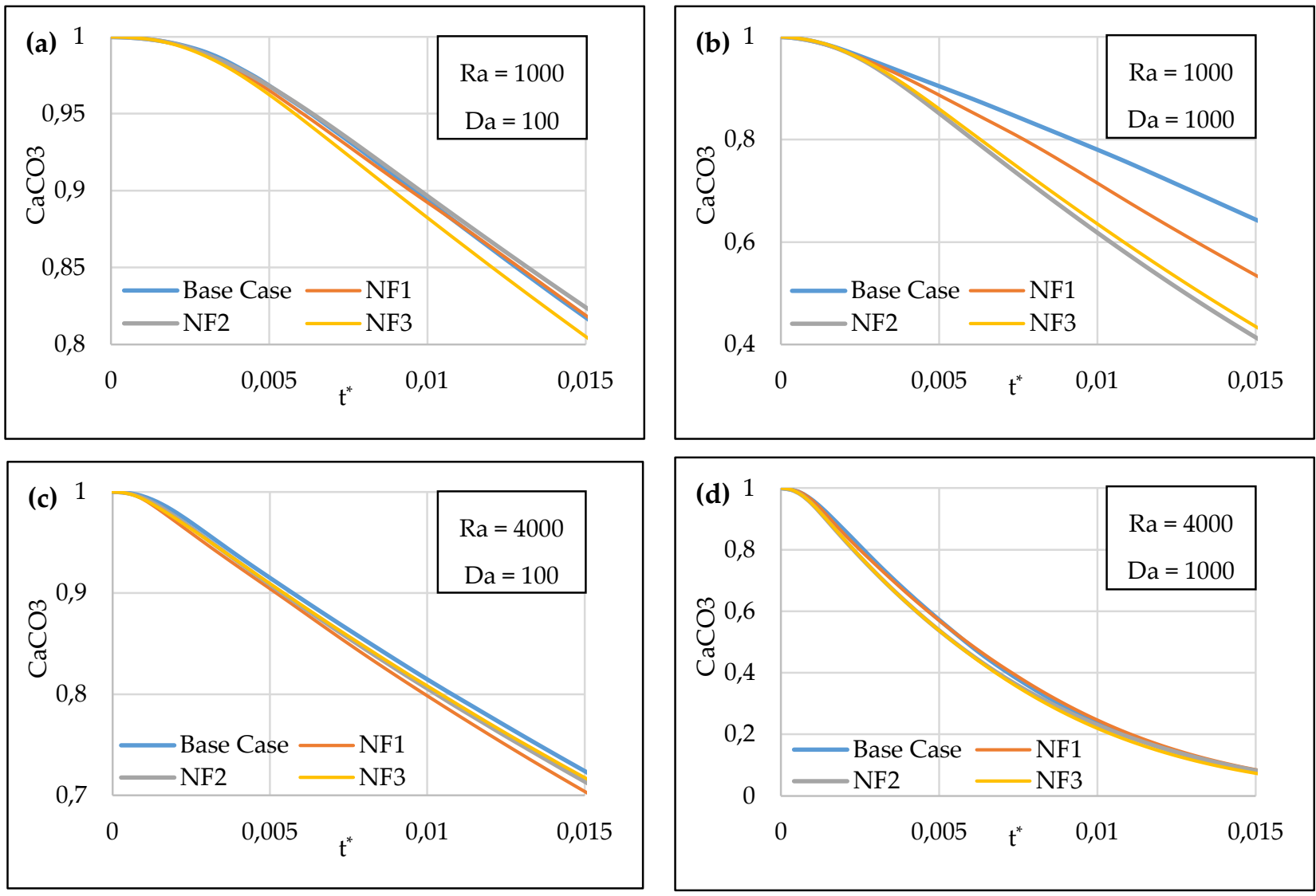

Fig. 15. Time variation of the average concentration of $\mathrm{CaCO}_{3}$ over time in the domain for the reactive network of fracture scenario at different combinations of $R a$ and $D a$.

\subsection{Outcrop Analogues}

In this section, we examine how fractures in rocks control the migration and trapping of injected dissolved $\mathrm{CO}_{2}$ in deep geological formations. For this aim, an outcrop analogue of volcanic basalt rocks in Lebanon is considered, and it contains various types of fractures with different sizes of aperture as shown in Fig. 15. We have selected a rectangle as a reservoir with a horizontal width of $100(\mathrm{~m})$ and a height of $50(\mathrm{~m})$, which here is referred to as real case. For simplicity, we assume that there are big $(2 \mathrm{~cm})$, medium $(1 \mathrm{~cm})$, and small $(0.5 \mathrm{~cm})$ aperture sizes of fractures. The initial and boundary conditions of the real case are the same as the conceptual model, and the physical parameters are summarized in Table 3 . To determine the effect of fractures on the migration behavior of dissolved $\mathrm{CO}_{2}$ plume and to evaluate the reactive-convective mixing, the homogeneous and fractured domains are 
simulated for different rates of reactions. For the fractured domain, we consider two cases. In the first one (case 1), we neglect the thin fractures to reduce model complexity; thus exclusively, the biggest fractures are included. In the second one (case 2) we consider fractures with all sizes of aperture.

The concentration distribution of dissolved $\mathrm{CO}_{2}$ in the homogeneous case and two fractured cases for different rates of reaction at $t^{*}=0.315$ (the equivalent of 10 years) are presented in Fig. 16. In each case, we explore the results for no reaction $\left(k_{r} a_{v}=0\right)$, slow reaction $\left(k_{r} a_{v}=5 \times 10^{-10} \mathrm{~m}^{3} \cdot \mathrm{s}^{-1} \cdot \mathrm{mol}^{-1}\right)$, and fast reaction $\left(k_{r} a_{v}=5 \times 10^{-9} \mathrm{~m}^{3} \cdot \mathrm{s}^{-1} \cdot \mathrm{mol}^{-1}\right)$. First of all, it is obvious that as the rate of reaction increases in the domain, the dissolved $\mathrm{CO}_{2}$ plume over the domain decreases due to the enhancement of the dissolution of $\mathrm{CO}_{2}$ in reaction with $\mathrm{CaCO}_{3}$. In Fig. 16, we can clearly see that the rate of reaction affects the amount of dissolved $\mathrm{CO}_{2}$ distributed in each case. Also, we observe that the heterogeneity leads to an increase of the $\mathrm{CO}_{2}$ plume in the surface area. Comparing case 1 and case 2 of the fractured cases shows that adding more different types of fractures helps the spreading of dissolved $\mathrm{CO}_{2}$ in the domain, and the heterogeneity helps the spreading of dissolved $\mathrm{CO}_{2}$ by passing the plume flow through the fracture. In case 2 the existence of thin fractures (Other than the ones with big aperture) causes the dissolved $\mathrm{CO}_{2}$ to distribute more over the domain. Moreover, the domain is more sensitive to heterogeneity when there is no reaction, and for a higher rate of reaction, we can see that the spreading of the dissolved $\mathrm{CO}_{2}$ through the fractures is less. For instance, for the high-reactive domain, heterogeneity has the lowest effect on $\mathrm{CO}_{2}$ distribution.

Fig. 17 illustrates the dimensionless total flux of $\mathrm{CO}_{2}$ entering the domain from the top boundary $\left(\mathrm{TF}^{*}\right.$ top $)$ during $\mathrm{t}^{*}=0.315$. To begin with, the fractured cases rather than homogeneous case, and also, the case with higher heterogeneity (case 2) rather than the case with lower heterogeneity (case 1 ) have higher $\mathrm{TF}^{*}{ }_{\text {top }}$, since the fractures help the dissolved 
$\mathrm{CO}_{2}$ to spread over the domain generally. As a result, the need for entering total flux will increase in the domain. In the homogeneous case, like the conceptual model, the values of $\mathrm{TF}^{*}$ top for the fast-reactive domain is more than the slow-reactive domain, and we see as the reaction rate increases, the total entering flux of $\mathrm{CO}_{2}$ gets higher. As noted before, this is because the reaction between $\mathrm{CO}_{2}$ and $\mathrm{CaCO}_{3}$ will increase the gradient of $\mathrm{CO}_{2}$ concentration at the top boundary, and consequently, there would be an increase in the rate of entering total flux of $\mathrm{CO}_{2}$. However, we cannot see this trend in the two other fractured cases in Fig. 17. This can be attributed to the fact that some fractures in the domain may have a restrictive role in spreading the flow of dissolved $\mathrm{CO}_{2}$, and for different reaction rates in fractured cases, the dissolved $\mathrm{CO}_{2}$ plumes can be hindered in the face with some fractures in their growth pathway. Furthermore, this figure shows that the effect of the reaction is more when we have all types of fractures (Case 2) than when we have just the fractures with big aperture (Case $1)$; in other words, the case with higher heterogeneity is more sensitive to the reaction rate. Fig. 18 represents the variation of the average concentration of $\mathrm{CaCO}_{3}$ for the slow and fast reactive cases. It is clear that for all the cases when there is a fast reaction, the domain has more dissolution of $\mathrm{CaCO}_{3}$, and the average concentration of $\mathrm{CaCO}_{3}$ decreases more in comparison to the slow-reactive cases. The mentioned point that the cases with higher heterogeneity are more sensitive to the reaction rate can be seen in this figure, and the difference between the slow reaction and fast reaction curves is increasing from homogeneous case to the fractured-case 2 . 


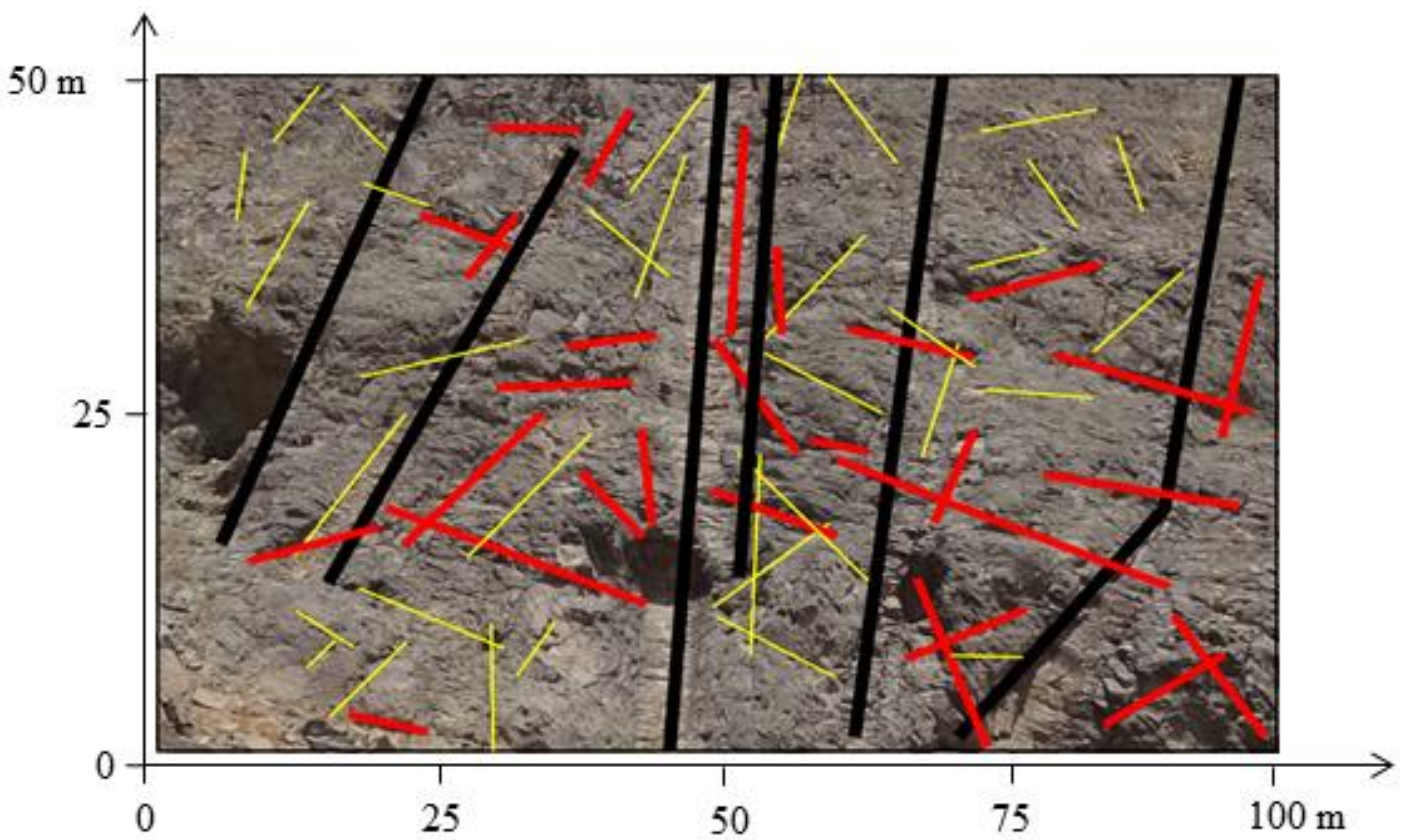

Fig. 16. Photograph showing the outcrop of volcanic basalt rocks in Lebanon. Three sizes of aperture for the fractures are considered in this case: The black, red, and yellow lines represent fractures with large $(2 \mathrm{~cm})$, medium $(1 \mathrm{~cm})$, and small $(0.5 \mathrm{~cm})$ aperture, respectively. 
Table 3. Physical parameters used for the real case.

\begin{tabular}{ccc}
\hline Parameter & Variable & Value \\
Length & $L$ & $100(\mathrm{~m})$ \\
Height & $H$ & $50(\mathrm{~m})$ \\
Density of fresh-water & $\rho_{0}$ & $1000\left(\mathrm{~kg} / \mathrm{m}^{3}\right)$ \\
Density of CO -water at the top $_{\text {boundary }}$ & $\rho_{s}$ & $1010\left(\mathrm{~kg} / \mathrm{m}^{3}\right)$ \\
Concentration at the top boundary & $c_{b}$ & $1+A . \sin (2 \pi x / \lambda)$ \\
Amplitude & $A$ & $0.01[-]$ \\
Wavelength of sinusoidal perturbation & $\lambda$ & $1 / 12(\mathrm{~m})$ \\
Porosity of the medium & $\varepsilon_{m}$ & $0.1[-]$ \\
Porosity of fracture & $\varepsilon_{f}$ & $0.3[-]$ \\
Diffusion coefficient & $D_{m}$ & $1 \times 10^{-9}(\mathrm{~m} / \mathrm{s})$ \\
Dynamic viscosity & $\mu$ & $5 \times 10^{-4}(\mathrm{~kg} /(\mathrm{m} \cdot \mathrm{s}))$ \\
Gravitational acceleration & $G$ & $9.8\left(\mathrm{~m} / \mathrm{s}^{2}\right)$ \\
Pressure at the top boundary & $P_{b}$ & $10(\mathrm{MPa})$ \\
longitudinal dispersivity & $\alpha_{L}$ & $1(\mathrm{~m})$ \\
transverse dispersivity & $\alpha_{T}$ & $0.1(\mathrm{~m})$ \\
Fracture dispersivity & $\alpha_{F}$ & $1(\mathrm{~m})$ \\
Intrinsic permeability of the medium & $k_{m}$ & $\left.1 \times 10^{-13}(\mathrm{~m})^{2}\right)$ \\
Intrinsic permeability of fracture & $k_{f}$ & $1 \times 10^{-9}\left(\mathrm{~m}^{2}\right)$ \\
Fracture aperture & $2 b$ & $0.5,1,2(\mathrm{~cm})$ \\
Rate of reaction & $k_{r} a_{v}$ & $0,5 \times 10^{-10}, 5 \times 10^{-9}\left(\mathrm{~m}^{3} /(\mathrm{s} . \mathrm{mol})\right)$ \\
\hline
\end{tabular}


No reaction
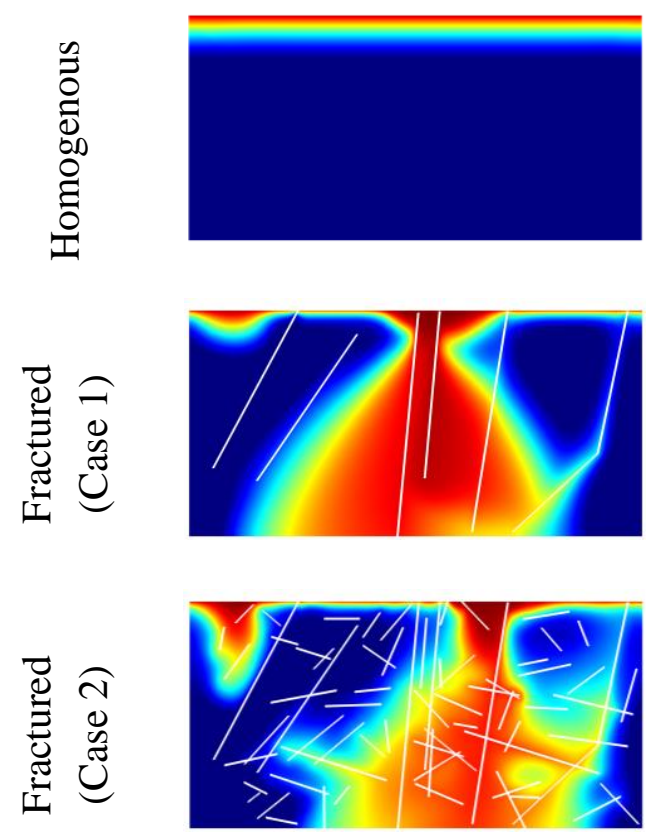

Slow reaction
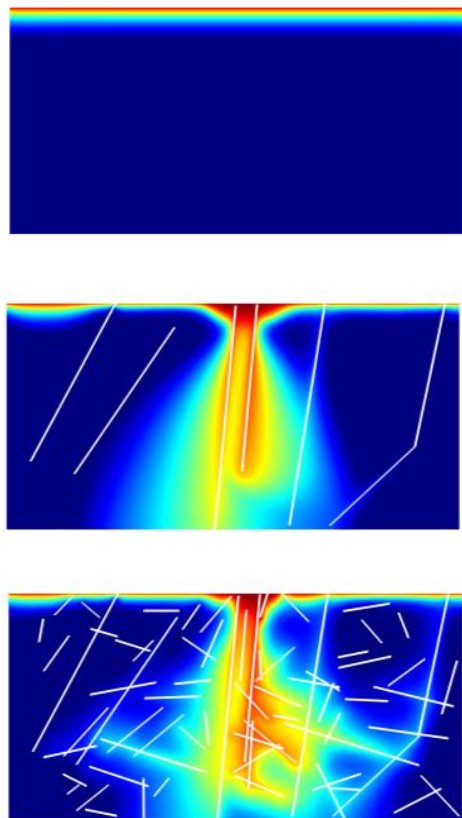

Fast reaction
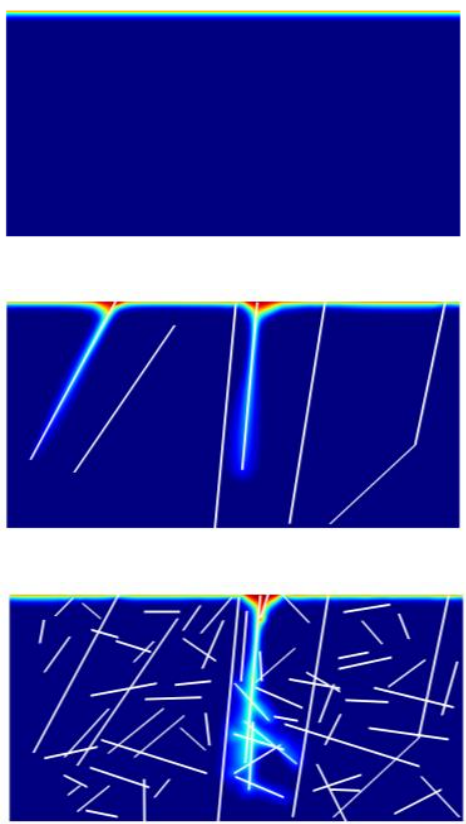

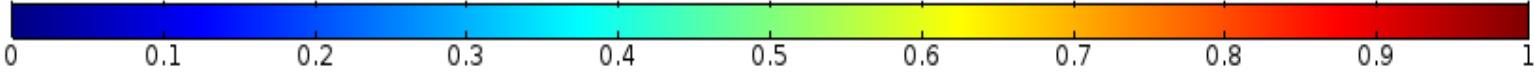

Fig. 17. Plume migration of the injected $\mathrm{CO}_{2}$ in the homogeneous and fractured cases for no reaction, low rate of reaction, and high rate of reaction after 10 years of simulation time.

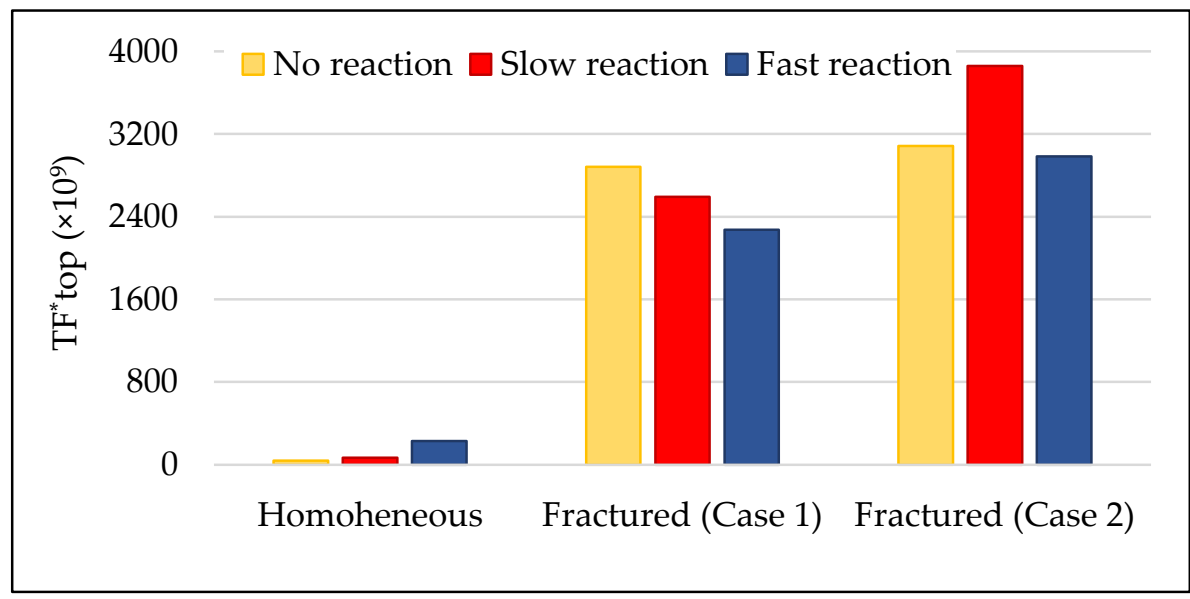

Fig. 18. Time integration of the dimensionless total flux of $\mathrm{CO}_{2}$ at the top boundary ( $\mathrm{TF}^{*}{ }_{\text {top }}$ ) for the homogeneous case, the fractured case contains fractures with big aperture (case 1), and the fractured case contains fractures with all sizes of aperture (case 2). 


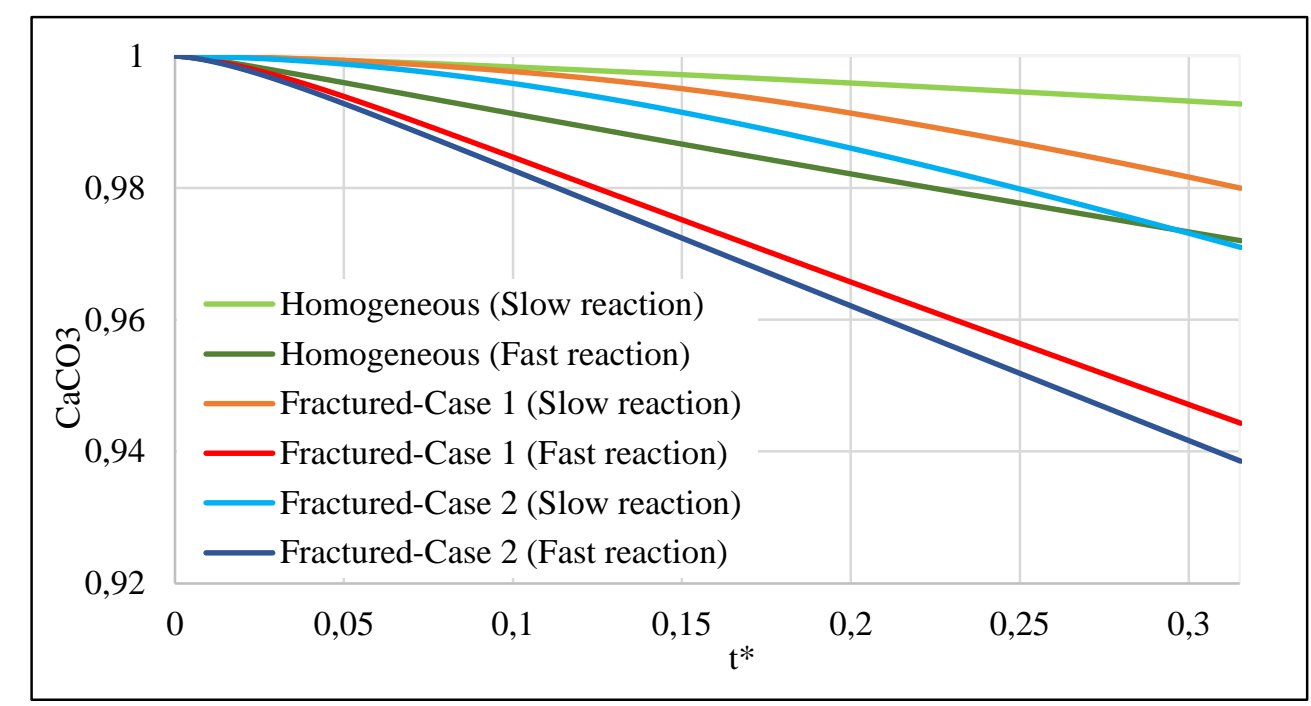

Fig. 19. Time variation of average concentration of $\mathrm{CaCO}_{3}$ over time in the homogeneous and fractured cases for slow and fast reactions.

\section{Conclusion}

The geological sequestration of $\mathrm{CO}_{2}$ is the most efficient technique for reducing carbon emissions to the atmosphere. A crucial issue in improving this technique, for safe implementations and in assessing its ecological and geological impacts relies on a good understanding of the fate of $\mathrm{CO}_{2}$ in geological formations. Mainly the carbonic acid, resulting from $\mathrm{CO}_{2}$, is controlled by the density-driven convection (DDC) and dissolution processes. Fractures and faults can be found worldwide in several storage reservoirs/aquifers. In certain cases, fractures are stimulated, by hydraulic fracturing, in order to improve the storage capacity of aquifers. The effect of fractures on DDC during $\mathrm{CO} 2$ sequestration has been widely discussed in the literature, but previous works neglect the effect of dissolution and reaction. This work aims at addressing this gap by evaluating the effect of fractures on the coupled processes of DDC and mineral dissolution. Our methodology is based on numerical simulations that are commonly used to investigate $\mathrm{CO}_{2}$ for practical and theoretical purposes. A COMSOL model is developed to perform the simulation. Appropriate numerical 
techniques are selected to reduce the computational requirements while maintaining high accuracy. The model is first applied to a synthetic domain with hypothetical fractured configurations. The convective flow is controlled by the Rayleigh number while the dissolution rate can be represented by the Damköhler number. We explore different combinations of these non-dimensional parameters to evaluate the coupled effects of convection and mineral dissolution on the total flux of $\mathrm{CO}_{2}$, under different configurations of fracture characteristics and topology. For more representative geology, we apply the methodology on a large-scale outcrop of a volcanic basalt rock formation in Lebanon. Based on outcrop analogy we evaluate the capacity of fractured volcanic basalt rocks in trapping $\mathrm{CO}_{2}$. The main findings of each scenario are summarized separately in the following:

- Horizontal fracture scenario: For medium convective flow, when the reactions are fast, by neglecting horizontal fractures, the entering total flux of $\mathrm{CO}_{2}$ is underestimated, and if the reaction is slow, neglecting horizontal fracture will lead to overestimation of the total flux of $\mathrm{CO}_{2}$. For high convective flow, neglecting horizontal fractures will not affect the estimation of the total flux of $\mathrm{CO}_{2}$ that can be stored in the domain, especially for fast reactions. For slow reactions, the total flux of $\mathrm{CO}_{2}$ is slightly sensitive to the fractures. Also, it was found that horizontal fracture can help the mixing by convection and reaction processes in the domain, it can play a restrictive role in entering dissolved $\mathrm{CO}_{2}$, and when the position of the horizontal fracture is not near the top surface, it has less influence on the entering flux. Moreover, for all cases, reactions enhance the capacity of the domain in capturing $\mathrm{CO}_{2}$.

- Vertical fracture scenario: For medium convective flow, when we have a non-reactive domain, neglecting vertical fracture will lead to overestimation of the total flux of $\mathrm{CO}_{2}$, and when we have a reaction in the domain (especially for fast reaction), 
neglecting vertical fracture will lead to underestimation of the total flux of $\mathrm{CO}_{2}$. And high convective flow, we have the same results but with less intensity. Furthermore, it was observed that the vertical fractures could hinder the fingers from growing due to the upward flow of freshwater.

- Inclined fracture scenario: Regardless of the rate of the reaction, ignoring the inclined fracture with a low angle leads to an overestimation of the total flux of $\mathrm{CO}_{2}$, no matter the rate of the reaction. Also, ignoring the inclined fracture with a high angle leads to an underestimation of the total flux of $\mathrm{CO}_{2}$, especially for the fast-reaction cases. In general, we saw that the low angle fracture acts like horizontal fracture which inhibits the growth of fingers, and the high angle fracture acts like vertical fracture which helps the freshwater to transfer upward in the domain, and eventually, the medium angle of fracture appears to have a combination of these effects.

- Network of fractures scenario: By increasing the level of the orthogonal fractures, the total entering flux of dissolved $\mathrm{CO}_{2}$ from the top surface is higher, and the more the rate of reaction, the stronger this effect. This is true for both medium and high convective flow. Network of fractures behave as pathways that help the dissolution of dissolved $\mathrm{CO}_{2}$, and higher fracture density causes the plumes of dissolved $\mathrm{CO}_{2}$ to distribute more evenly throughout the domain especially for high-reactive cases.

- Outcrop analogs (Real case): For the case of a realistic fracture network, containing fractures with different apertures, lengths and separations, for all the rates of reaction, we saw that ignoring heterogeneity results in an underestimation of the storage capacity of the total entering flux of $\mathrm{CO}_{2}$. It is found that heterogeneity helps the spreading of dissolved $\mathrm{CO}_{2}$ by passing the plume flow through the fracture and leads to an increase of the $\mathrm{CO}_{2}$ plume in the surface area. This effect will be higher when 
there is less reaction in the domain; in other words, the domain is more sensitive to heterogeneity when there is no reaction, and for a higher rate of reaction, the spreading of the dissolved $\mathrm{CO}_{2}$ through the fractures is less.

The present work contributes to a better understanding of the impact of fractures on the mechanisms of $\mathrm{CO}_{2}$ trapping. However, there are many uncertainties in the input parameters for both static geological modeling and dynamic flow modeling. Future work should be directed to evaluation of the uncertainties related to fractures on model outputs. The effects of more complex/realistic geochemical reactions are worthy of investigation. Extension to 3D domain and fractures could be an interesting direction for future research. An important issue is also the influence of mineral dissolution on the fracture characteristics, which is neglected in this work.

\section{Acknowledgment and data availability}

Behzad Ataie-Ashtiani and Craig T. Simmons acknowledge support from the National Centre for Groundwater Research and Training, Australia. Behzad Ataie-Ashtiani also appreciates the support of the Research Office of the Sharif University of Technology, Iran. There is no data used in this modeling study. 


\section{Credit Author Statement}

Paiman Shafabakhsh: Conceptualization, Methodology, Investigation and WritingOriginal draft preparation; Behzad Ataie-Ashtiani : Conceptualization, Supervision and Review \& Editing; Craig T. Simmons: Writing - Review \& Editing and Supervision; Anis Younes : Methodology; Marwan Fahs : Conceptualization, Software, supervision, Writing - Review \& Editing and Funding acquisition 


\section{References}

Aminu, M.D., Nabavi, S.A., Rochelle, C.A., Manovic, V., 2017. A review of developments in carbon dioxide storage. Applied Energy 208, 1389-1419. https://doi.org/10.1016/j.apenergy.2017.09.015

Ataie-Ashtiani, B., Simmons, C.T., Werner, A.D., 2014. Influence of Boundary Condition Types on Unstable Density-Dependent Flow: B. Ataie-Ashtiani Ground Water xx, no. xx: xx-xx. Groundwater 52, 378-387. https://doi.org/10.1111/gwat.12067

Babaei, M., Islam, A., 2018. Convective-Reactive $\mathrm{CO}_{2}$ Dissolution in Aquifers with Mass Transfer with Immobile Water. Water Resour. Res. 54, 9585-9604. https://doi.org/10.1029/2018WR023150

Bachu, S., 2015. Review of CO2 storage efficiency in deep saline aquifers. International Journal of Greenhouse Gas Control 40, 188-202. https://doi.org/10.1016/j.ijggc.2015.01.007

Bachu, S., Bonijoly, D., Bradshaw, J., Burruss, R., Holloway, S., Christensen, N.P., Mathiassen, O.M., 2007. CO2 storage capacity estimation: Methodology and gaps. International Journal of Greenhouse Gas Control 1, 430-443. https://doi.org/10.1016/S1750-5836(07)00086-2

Boot-Handford, M.E., Abanades, J.C., Anthony, E.J., Blunt, M.J., Brandani, S., Mac Dowell, N., Fernández, J.R., Ferrari, M.-C., Gross, R., Hallett, J.P., Haszeldine, R.S., Heptonstall, P., Lyngfelt, A., Makuch, Z., Mangano, E., Porter, R.T.J., Pourkashanian, M., Rochelle, G.T., Shah, N., Yao, J.G., Fennell, P.S., 2014. Carbon capture and storage update. Energy Environ. Sci. 7, 130-189. https://doi.org/10.1039/C3EE42350F

Borrero-Santiago, A.R., Ribicic, D., Bonnail, E., Netzer, R., Koseto, D., Ardelan, M.V., 2020. Response of bacterial communities in Barents Sea sediments in case of a potential CO2 leakage from carbon reservoirs. Marine Environmental Research 160, 105050. https://doi.org/10.1016/j.marenvres.2020.105050

Brezonik, P.L., 2018. Chemical Kinetics and Process Dynamics in Aquatic Systems, 2nd ed. Routledge. https://doi.org/10.1201/9781315139135

Chaudhuri, A., Rajaram, H., Viswanathan, H., 2008. Alteration of fractures by precipitation and dissolution in gradient reaction environments: Computational results and stochastic analysis: APERTURE ALTERATION. Water Resour. Res. 44. https://doi.org/10.1029/2008WR006982

Chen, B., Harp, D.R., Lin, Y., Keating, E.H., Pawar, R.J., 2018. Geologic CO2 sequestration monitoring design: A machine learning and uncertainty quantification based approach. Applied Energy 225, 332-345. https://doi.org/10.1016/j.apenergy.2018.05.044

Dai, Z., Zhang, Y., Bielicki, J., Amooie, M.A., Zhang, M., Yang, C., Zou, Y., Ampomah, W., Xiao, T., Jia, W., Middleton, R., Zhang, W., Sun, Y., Moortgat, J., Soltanian, 
M.R., Stauffer, P., 2018. Heterogeneity-assisted carbon dioxide storage in marine sediments. Applied Energy 225, 876-883. https://doi.org/10.1016/j.apenergy.2018.05.038

Elkhoury, J.E., Ameli, P., Detwiler, R.L., 2013. Dissolution and deformation in fractured carbonates caused by flow of $\mathrm{CO} 2$-rich brine under reservoir conditions. International Journal of Greenhouse Gas Control 16, S203-S215. https://doi.org/10.1016/j.ijggc.2013.02.023

Emami-Meybodi, H., Hassanzadeh, H., Green, C.P., Ennis-King, J., 2015. Convective dissolution of $\mathrm{CO} 2$ in saline aquifers: Progress in modeling and experiments. International Journal of Greenhouse Gas Control 40, 238-266. https://doi.org/10.1016/j.ijggc.2015.04.003

Ennis-King, J., Paterson, L., 2007. Coupling of geochemical reactions and convective mixing in the long-term geological storage of carbon dioxide. International Journal of Greenhouse Gas Control 1, 86-93. https://doi.org/10.1016/S1750-5836(07)00034-5

Erfani, H., Babaei, M., Niasar, V., 2020. Signature of Geochemistry on Density-Driven CO Mixing in Sandstone Aquifers. Water Resour. Res. 56. https://doi.org/10.1029/2019WR026060

Fischer, S., Knopf, S., May, F., Rebscher, D., 2016. CO2 Storage related Groundwater Impacts and Protection. Grundwasser 21, 5-21. https://doi.org/10.1007/s00767-0150315-7

Fitts, J.P., Peters, C.A., 2013. Caprock Fracture Dissolution and CO2 Leakage. Reviews in Mineralogy and Geochemistry 77, 459-479. https://doi.org/10.2138/rmg.2013.77.13

$\mathrm{Fu}, \mathrm{X}$., Cueto-Felgueroso, L., Bolster, D., Juanes, R., 2015. Rock dissolution patterns and geochemical shutdown of -brine-carbonate reactions during convective mixing in porous media. J. Fluid Mech. 764, 296-315. https://doi.org/10.1017/jfm.2014.647

Ghesmat, K., Hassanzadeh, H., Abedi, J., 2011. The impact of geochemistry on convective mixing in a gravitationally unstable diffusive boundary layer in porous media: $\mathrm{CO}_{2}$ storage in saline aquifers. J. Fluid Mech. 673, 480-512. https://doi.org/10.1017/S0022112010006282

Ghoshal, P., Cardoso, S.S.S., 2018. Reactive convective-dissolution in a porous medium: stability and nonlinear dynamics. Phys. Chem. Chem. Phys. 20, 21617-21628. https://doi.org/10.1039/C8CP03064B

Gouch, C., 2016. Carbon capture and its storage: an integrated assessment. ROUTLEDGE, Place of publication not identified.

Hidalgo, J.J., Dentz, M., Cabeza, Y., Carrera, J., 2015. Dissolution patterns and mixing dynamics in unstable reactive flow: Mixing unstable reactive flow. Geophys. Res. Lett. 42, 6357-6364. https://doi.org/10.1002/2015GL065036

Hirthe, E.M., Graf, T., 2015. Fracture network optimization for simulating 2D variabledensity flow and transport. Advances in Water Resources 83, 364-375. https://doi.org/10.1016/j.advwatres.2015.07.001

Hoteit, H., Fahs, M., Soltanian, M.R., 2019. Assessment of CO2 Injectivity During Sequestration in Depleted Gas Reservoirs. Geosciences 9, 199. 
https://doi.org/10.3390/geosciences9050199

Huo, D., Gong, B., 2010. Numerical Simulation on CO2 Leakage through Fractures along Wells using Discrete Fracture Modeling, in: SPE Asia Pacific Oil and Gas Conference and Exhibition. Presented at the SPE Asia Pacific Oil and Gas Conference and Exhibition, Society of Petroleum Engineers, Brisbane, Queensland, Australia. https://doi.org/10.2118/133986-MS

Iding, M., Ringrose, P., 2010. Evaluating the impact of fractures on the performance of the In Salah CO2 storage site. International Journal of Greenhouse Gas Control 4, 242 248. https://doi.org/10.1016/j.ijggc.2009.10.016

Islam, A., Sun, A.Y., Yang, C., Skea, J., Shukla, P.R., Pirani, A., Moufouma-Okia, W., Péan, C., Pidcock, R., Connors, S., Matthews, J.B.R., Chen, Y., Zhou, X., Gomis, M.I., Lonnoy, E., Maycock, T., Tignor, M., Waterfield, T., 2016a. Reactive Transport Modeling of the Enhancement of Density-Driven CO2 Convective Mixing in Carbonate Aquifers and its Potential Implication on Geological Carbon Sequestration. Sci Rep 6, 24768. https://doi.org/10.1038/srep24768

Islam, A.W., Meckel, T.A., Sun, A.Y., Krishnamurthy, P.G., 2016b. Numerical experiments of density driven $\mathrm{CO} 2$ saturated brine migration in heterogeneous two-dimensional geologic fabric materials. International Communications in Heat and Mass Transfer 71, 148-156. https://doi.org/10.1016/j.icheatmasstransfer.2015.12.019

Izgec, O., Demiral, B., Bertin, H.J., Akin, S., 2005. Experimental and Numerical Investigation of Carbon Sequestration in Saline Aquifers, in: SPE/EPA/DOE Exploration and Production Environmental Conference. Presented at the SPE/EPA/DOE Exploration and Production Environmental Conference, Society of Petroleum Engineers, Galveston, Texas. https://doi.org/10.2118/94697-STU

Jafari Raad, S.M., Hassanzadeh, H., 2018. Onset of density-driven instabilities in fractured aquifers. Phys. Rev. E 97, 043109. https://doi.org/10.1103/PhysRevE.97.043109

Jafari Raad, S.M., Hassanzadeh, H., 2017. Prospect for storage of impure carbon dioxide streams in deep saline aquifers-A convective dissolution perspective. International Journal of Greenhouse Gas Control 63, 350-355. https://doi.org/10.1016/j.ijggc.2017.06.011

Kim, M., Kim, K., Han, W.S., Oh, J., Park, E., 2019. Density-Driven Convection in a Fractured Porous Media: Implications for Geological $\mathrm{CO}_{2}$ Storage. Water Resour. Res. 55, 5852-5870. https://doi.org/10.1029/2019WR024822

Kim, Y., Jang, H., Kim, J., Lee, J., 2017. Prediction of storage efficiency on CO2 sequestration in deep saline aquifers using artificial neural network. Applied Energy 185, 916-928. https://doi.org/10.1016/j.apenergy.2016.10.012

Kong, X.-Z., Saar, M.O., 2013. Numerical study of the effects of permeability heterogeneity on density-driven convective mixing during $\mathrm{CO} 2$ dissolution storage. International Journal of Greenhouse Gas Control 19, 160-173. https://doi.org/10.1016/j.ijggc.2013.08.020

Koohbor, B., Fahs, M., Ataie-Ashtiani, B., Belfort, B., Simmons, C.T., Younes, A., 2019. Uncertainty analysis for seawater intrusion in fractured coastal aquifers: Effects of 
fracture location, aperture, density and hydrodynamic parameters. Journal of Hydrology 571, 159-177. https://doi.org/10.1016/j.jhydrol.2019.01.052

Li, D., Jiang, X., 2017. Numerical investigation of the partitioning phenomenon of carbon dioxide and multiple impurities in deep saline aquifers. Applied Energy 185, 14111423. https://doi.org/10.1016/j.apenergy.2015.12.113

Liu, P., Yao, J., Couples, G.D., Huang, Z., Sun, H., Ma, J., 2017. Numerical modelling and analysis of reactive flow and wormhole formation in fractured carbonate rocks. Chemical Engineering Science 172, 143-157. https://doi.org/10.1016/j.ces.2017.06.027

Marini, L., 2007. Geological sequestration of carbon dioxide: thermodynamics, kinetics, and reaction path modeling, 1st ed. ed, Developments in geochemistry. Elsevier, Amsterdam ; Boston.

Martinez, M.J., Hesse, M.A., 2016. Two-phase convective $\mathrm{CO} 2$ dissolution in saline aquifers. Water Resour. Res. 52, 585-599. https://doi.org/10.1002/2015WR017085

Masson-Delmotte, V.P., Zhai, P., Pörtner, H.-O., Roberts, D., 2018. Summary for Policymakers. In: Global Warming of $1.5^{\circ} \mathrm{C}$. An IPCC Special Report on the impacts of global warming of $1.5^{\circ} \mathrm{C}$ above pre-industrial levels and related global greenhouse gas emission pathways, in the context of strengthening the global response to the threat of climate change, sustainable development, and efforts to eradicate poverty. IPCC.

Matter, J.M., Takahashi, T., Goldberg, D., 2007. Experimental evaluation of in situ $\mathrm{CO}_{2}$ water-rock reactions during $\mathrm{CO}_{2}$ injection in basaltic rocks: Implications for geological $\mathrm{CO}_{2}$ sequestration: $\mathrm{CO}_{2}$. Geochem. Geophys. Geosyst. 8, n/a-n/a. https://doi.org/10.1029/2006GC001427

Michael, K., Golab, A., Shulakova, V., Ennis-King, J., Allinson, G., Sharma, S., Aiken, T., 2010. Geological storage of CO2 in saline aquifers-A review of the experience from existing storage operations. International Journal of Greenhouse Gas Control 4, 659667. https://doi.org/10.1016/j.ijggc.2009.12.011

Middleton, R., Viswanathan, H., Currier, R., Gupta, R., 2014. CO2 as a fracturing fluid: Potential for commercial-scale shale gas production and $\mathrm{CO} 2$ sequestration. Energy Procedia 63, 7780-7784. https://doi.org/10.1016/j.egypro.2014.11.812

Mojtaba, S., Behzad, R., Rasoul, N.M., Mohammad, R., 2014. Experimental study of densitydriven convection effects on $\mathrm{CO} 2$ dissolution rate in formation water for geological storage. Journal of Natural Gas Science and Engineering 21, 600-607. https://doi.org/10.1016/j.jngse.2014.09.020

Molari, M., Guilini, K., Lott, C., Weber, M., de Beer, D., Meyer, S., Ramette, A., Wegener, G., Wenzhöfer, F., Martin, D., Cibic, T., De Vittor, C., Vanreusel, A., Boetius, A., 2018. $\mathrm{CO}_{2}$ leakage alters biogeochemical and ecological functions of submarine sands. Sci. Adv. 4, eaao2040. https://doi.org/10.1126/sciadv.aao2040

Mozafari, B., Fahs, M., Ataie-Ashtiani, B., Simmons, C.T., Younes, R., 2018. On the use of COMSOL Multiphysics for seawater intrusion in fractured coastal aquifers. E3S Web Conf. 54, 00020. https://doi.org/10.1051/e3sconf/20185400020 
NASA Global climate change, 2018. Vital Signs of the Planet.

Orr, F.M., 2009. Onshore Geologic Storage of CO2. Science 325, 1656-1658. https://doi.org/10.1126/science.1175677

Prasad, A., Simmons, C.T., 2003. Unstable density-driven flow in heterogeneous porous media: A stochastic study of the Elder [1967b] "short heater" problem. Water Resour. Res. 39, SBH 4-1-SBH 4-21. https://doi.org/10.1029/2002WR001290

Raziperchikolaee, S., Alvarado, V., Yin, S., 2013. Effect of hydraulic fracturing on long-term storage of $\mathrm{CO} 2$ in stimulated saline aquifers. Applied Energy 102, 1091-1104. https://doi.org/10.1016/j.apenergy.2012.06.043

Raziperchikolaee, S., Babarinde, O., Sminchak, J., Gupta, N., 2019. Natural fractures within Knox reservoirs in the Appalachian Basin: characterization and impact on poroelastic response of injection. Greenhouse Gas Sci Technol 9, 1247-1265. https://doi.org/10.1002/ghg.1933

Raziperchikolaee, S., Pasumarti, A., Mishra, S., 2020. The effect of natural fractures on CO 2 storage performance and oil recovery from $\mathrm{CO}_{2}$ and WAG injection in an Appalachian basin reservoir. Greenhouse Gas Sci Technol 10, 1098-1114. https://doi.org/10.1002/ghg.2028

Rochelle, C.A., Pearce, J.M., Holloway, S., 1999. The underground sequestration of carbon dioxide: containment by chemical reactions in the deep geosphere. Geological Society, London, Special Publications 157, 117-129. https://doi.org/10.1144/GSL.SP.1999.157.01.09

Rogelj, J., den Elzen, M., Höhne, N., Fransen, T., Fekete, H., Winkler, H., Schaeffer, R., Sha, F., Riahi, K., Meinshausen, M., 2016. Paris Agreement climate proposals need a boost to keep warming well below $2{ }^{\circ} \mathrm{C}$. Nature 534, 631-639. https://doi.org/10.1038/nature18307

Romasheva, N., Ilinova, A., 2019. CCS Projects: How Regulatory Framework Influences Their Deployment. Resources 8, 181. https://doi.org/10.3390/resources8040181

Rose, S.K., Richels, R., Blanford, G., Rutherford, T., 2017. The Paris Agreement and next steps in limiting global warming. Climatic Change 142, 255-270. https://doi.org/10.1007/s10584-017-1935-y

Sainz-Garcia, A., Abarca, E., Nardi, A., Grandia, F., Oelkers, E.H., 2017. Convective mixing fingers and chemistry interaction in carbon storage. International Journal of Greenhouse Gas Control 58, 52-61. https://doi.org/10.1016/j.ijggc.2016.12.005

Shafabakhsh, P., Fahs, M., Ataie-Ashtiani, B., Simmons, C.T., 2019. Unstable DensityDriven Flow in Fractured Porous Media: The Fractured Elder Problem. Fluids 4, 168. https://doi.org/10.3390/fluids4030168

Sigfusson, B., Gislason, S.R., Matter, J.M., Stute, M., Gunnlaugsson, E., Gunnarsson, I., Aradottir, E.S., Sigurdardottir, H., Mesfin, K., Alfredsson, H.A., Wolff-Boenisch, D., Arnarsson, M.T., Oelkers, E.H., 2015. Solving the carbon-dioxide buoyancy challenge: The design and field testing of a dissolved $\mathrm{CO} 2$ injection system. International Journal of Greenhouse Gas Control 37, 213-219. https://doi.org/10.1016/j.ijggc.2015.02.022 
Simmons, C.T., Sharp, J.M., Nield, D.A., 2008. Modes of free convection in fractured lowpermeability media. Water Resour. Res. 44. https://doi.org/10.1029/2007WR006551

Singh, H., Islam, A., 2018. Enhanced safety of geologic CO2 storage with nanoparticles. International Journal of Heat and Mass Transfer 121, 463-476. https://doi.org/10.1016/j.ijheatmasstransfer.2017.12.152

Soltanian, M.R., Hajirezaie, S., Hosseini, S.A., Dashtian, H., Amooie, M.A., Meyal, A., Ershadnia, R., Ampomah, W., Islam, A., Zhang, X., 2019. Multicomponent reactive transport of carbon dioxide in fluvial heterogeneous aquifers. Journal of Natural Gas Science and Engineering 65, 212-223. https://doi.org/10.1016/j.jngse.2019.03.011

Tang, Y., Li, Z., Wang, R., Cui, M., Wang, X., Lun, Z., Lu, Y., 2019. Experimental Study on the Density-Driven Carbon Dioxide Convective Diffusion in Formation Water at Reservoir Conditions. ACS Omega 4, 11082-11092. https://doi.org/10.1021/acsomega.9b00627

Ward, T.J., Jensen, O.E., Power, H., Riley, D.S., 2015. Substrate degradation in highRayleigh-number reactive convection. Phys. Fluids 27, 116601. https://doi.org/10.1063/1.4935226

Xu, T., Apps, J.A., Pruess, K., 2004. Numerical simulation of CO2 disposal by mineral trapping in deep aquifers. Applied Geochemistry 19, 917-936. https://doi.org/10.1016/j.apgeochem.2003.11.003

Zhang, L., Zhang, S., Jiang, W., Wang, Z., Li, J., Bian, Y., 2018. A mechanism of fluid exchange associated to $\mathrm{CO} 2$ leakage along activated fault during geologic storage. Energy 165, 1178-1190. https://doi.org/10.1016/j.energy.2018.09.104

Zhang, W., Li, Y., Omambia, A.N., 2011. Reactive transport modeling of effects of convective mixing on long-term $\mathrm{CO} 2$ geological storage in deep saline formations. International Journal of Greenhouse Gas Control 5, 241-256. https://doi.org/10.1016/j.ijggc.2010.10.007 